\title{
The anatomy of the basal turtle Eileanchelys waldmani from the Middle Jurassic of Isle of Skye, Scotland
}

\author{
Jérémy Anquetin ${ }^{1,2 *}$
}

1Department of Palaeontology, The Natural History Museum, Cromwell Road, London SW7 5BD, United Kingdom ${ }^{2}$ Research Department of Cell and Developmental Biology, UCL, University College London, Gower Street, London WC1E 6BT, United Kingdom

*Corresponding author: jeremy.anquetin@jurassica.ch

\begin{abstract}
The stem turtle Eileanchelys waldmani is known from the Bathonian deposits of the Kilmaluag Formation, Isle of Skye, Scotland. A description of all the currently available material, including several skulls and shells, is provided herein. Eileanchelys waldmani is characterised by a mosaic of plesiomorphic and derived features. The former include a flat vomer, a reduced posterior extension of the pterygoid, the absence of flooring of the cavum acustico-jugulare, the absence of proper recessus scalae tympani, wide vertebral scales, a vertebral 3-4 sulcus on neural 6, a pair of mesoplastra meeting medially, and platycoelous cervical vertebrae. Derived features include a prefrontal-vomer contact, an elongate postorbital skull, a well-developed antrum postoticum, and a slender processus interfenestralis of the opisthotic. Eileanchelys waldmani also possesses unique features such as a possible ninth neural or supernumerary suprapygal of remarkable shape, as well as a broad first suprapygal that contacts the peripherals laterally. Additionally, E. waldmani documents the evolution of the vomer and basicranium from basalmost turtles to the crown-group.
\end{abstract}


Until recently, the Middle Jurassic fossil record of turtles was scarce. Most known remains consisted of shells from deposits in China (Sichuan and Xinjiang Provinces), Kyrgyzstan and Thailand (e.g., Young \& Chow 1953; Ye 1982, 1994; Fang 1987; Nessov 1995; Ye \& Pi 1997; Tong et al. 2002; Matzke et al. 2005). Most of these remains have been referred to chengyuchelyids and xinjiangchelyids, which are usually considered to be basal eucryptodires (e.g., Joyce 2007; Danilov \& Parham 2008). Apart from these Asiatic taxa, the United Kingdom was the only other place where notable Middle Jurassic turtle remains were found: Kirtlington (upper Bathonian, Oxfordshire) yielded fragmented remains of a pleurosternid and an indeterminate cryptodire (Gillham 1994; Scheyer \& Anquetin 2008), whereas Stonesfield (early middle Bathonian, Oxfordshire) yielded fossil epidermal scales of an indeterminate turtle (Anquetin \& Claude 2008). Our knowledge of Middle Jurassic turtles improved in the past few years with the discovery of two stem taxa: Heckerochelys romani Sukhanov, 2006 from Russia, and Condorchelys antiqua Sterli, 2008 from Argentina. These two species are known from partial cranial and postcranial material, and help to bridge the morphological gap between the basalmost turtles and the crown-group. Recently, Anquetin et al. (2009) announced the discovery of a new stem turtle from the Bathonian of the Isle of Skye, Scotland. Eileanchelys waldmani Anquetin et al., 2009 is known from cranial and postcranial remains of several individuals and represents the most complete Middle Jurassic turtle known to date. The present contribution provides a thorough description of the currently available material and a discussion of the morphology of this basal species in the context of the evolution of early turtles.

In 1971, a geology field party from Stowe School (Buckinghamshire) found vertebrate bones in loose blocks that had fallen from the cliffs on the north side of Glen Scaladal (Cladach a'Ghlinne, [NG 519 165], locality discovered by M. Waldman) on the Strathaird Peninsula, Isle of Skye, Scotland (Fig. 1). Throughout the 1970s, several workers, including M. Waldman and the late R. J. G. Savage, returned to the locality and collected further material (see Waldman \& Evans 1994). The study of this material resulted in several publications that concentrated on the mammal, lepidosauromorph and amphibian remains (Waldman \& Savage 1972; Savage 1984; Waldman \& Evans 1994; Evans \& Waldman 1996). In 2004, funds were granted to S. E. Evans (UCL) by the National Geographic Society to organise fieldwork at Cladach a'Ghlinne. The field party was led by S. E. Evans, P. M. Barrett (NHM) and J. Hilton (then of the NMS), and was further composed of researchers, technicians and students from UCL, NHM, NMS, and the Universities of
Cambridge and Birmingham. During four weeks in Spring 2004, a large amount of vertebrate material was collected (Barrett 2006; Evans et al. 2006), including most of the turtle material described herein.

Institutional abbreviations. BP, Bernard Price Institute for Palaeontological Research, University of the Witwatersrand, Johannesburg, South Africa; MB, Museum für Naturkunde, Humboldt Universität, Berlin, Germany; MCZ, Museum of Comparative Zoology, Harvard University, Cambridge, Massachusetts, USA; MNA, Museum of Northern Arizona, Flagstaff, Arizona, USA; NHM, Natural History Museum, London, UK; NMS, National Museums of Scotland, Edinburgh, UK; SMNS, Staatliches Museum für Naturkunde, Stuttgart, Germany; TMM, Texas Memorial Museum, Austin, Texas, USA; UCL, University College London, London, UK.

\section{Geological setting}

Cladach a'Ghlinne represents the best exposure of the Kilmaluag Formation ('Ostracod Limestones' of previous nomenclature). This formation is part of the Great Estuarine Group (GEG), which consists of a sequence of Middle Jurassic paralic deposits on the islands of the Inner Hebrides, NW Scotland. The GEG crops out in the isles of Skye, Raasay, Eigg and Muck and is intercalated conformably within the marine Jurassic section of the Minch Basin (Harris \& Hudson 1980; Hudson 1983). The GEG is remarkable as it yields no marine fauna but brackish and/or freshwater assemblages; it is the only part of the Jurassic section of the Minch Basin that is not fully marine (Harris \& Hudson 1980).

The Kilmaluag formation is divided into fourteen beds (Harris \& Hudson 1980, fig. 9; Andrews 1985, fig. 4). The lower beds ( 1 to 9) represent an alternation between clastic and carbonate mud deposition in a low-salinity lagoon. Bed 9 corresponds to the 'Vertebrate Beds' from which the vertebrate material is collected. These layers consist of limestones with abundant remains of the gastropod Viviparus and fragments of vertebrate bones. According to Andrews (1985, p. 1128), "these beds may represent a wet climatic phase in the history of the shallow lagoons" (i.e., a freshening phase). The upper beds (10 to 14) are characterised by a return to sublittoral lagoonal conditions with increased marine influences.

The locality is located on the foreshore north to the mouth of Glen Scaladal, on the west coast of the Strathaird Peninsula (Fig. 1). The cliff section at Cladach a'Ghlinne exposes the sediments of the Kilmaluag Formation. This is a protected area (Sites of Special Scientific Interest - SSSI) and collecting is consequently 


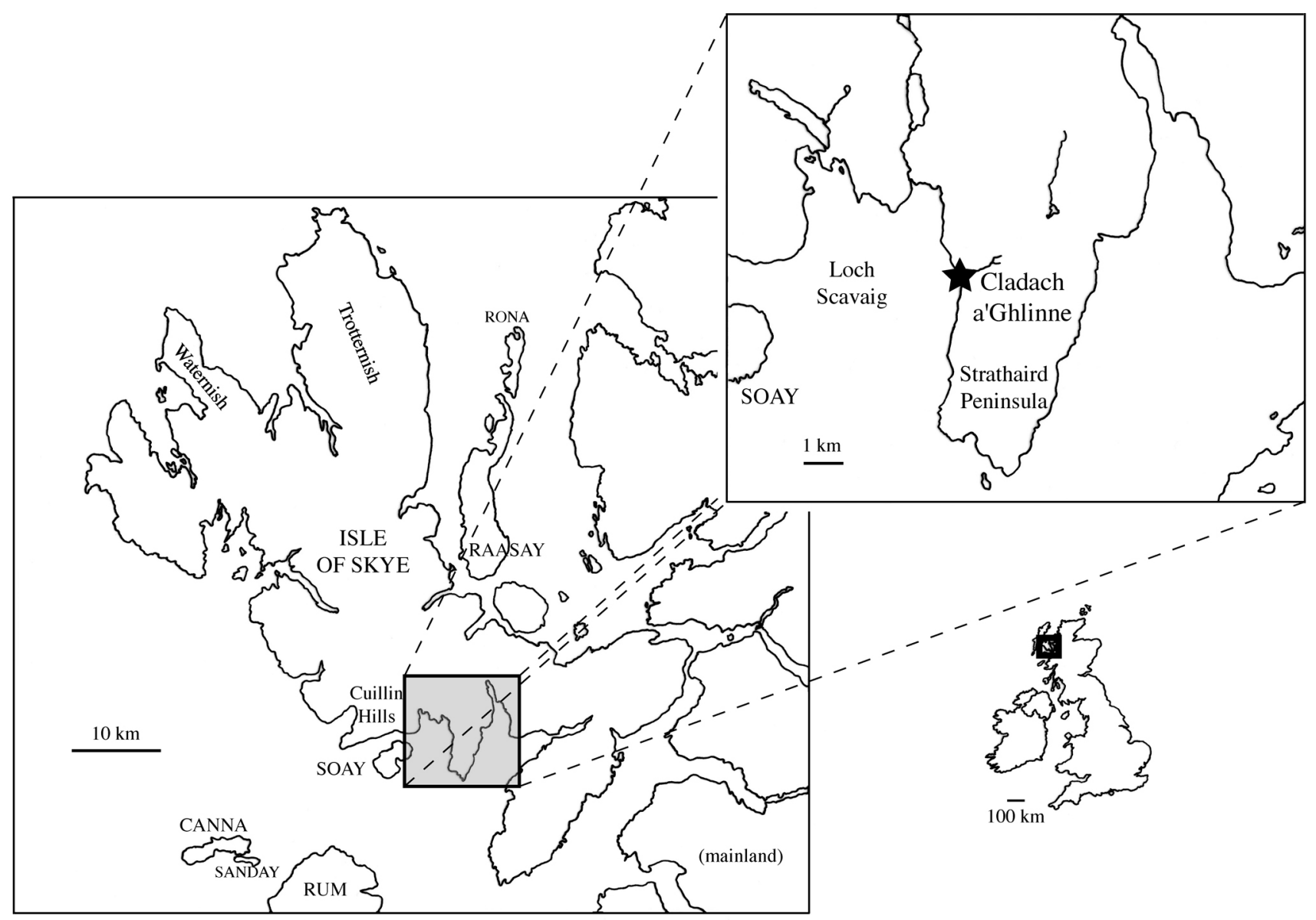

Figure 1 - Localisation of the Cladach a'Ghlinne locality, Strathaird Peninsula, Isle of Skye, Inner Hebrides, Scotland.

restricted to the fallen boulders on the beach. Early Tertiary igneous activity produced numerous sills and dikes that chemically altered and hardened the sediments (Savage 1984). This makes fossil extraction on the field, and subsequent fossil preparation, extremely difficult.

\section{Material and methods}

The majority of the material described herein was collected during the 2004 fieldwork, including the holotype and paratypes (see section 3). The paratypes consist of an association of five or six turtles within a single large block (Fig. 2). Additional material was collected in the 1970s by M. Waldman and R. J. G. Savage, and later by M. Waldman and S. E. Evans (see 'Referred specimens' in section 3). A few of these specimens were prepared by M. Waldman and S. Finney (University of Cambridge). The material collected in 2004 was prepared at the NHM by the author (paratype association) and S. Moore-Fay (holotype and NMS G 2004.31.17).

The present paper follows the anatomical nomenclatures established by Zangerl (1969) for the shell and Gaffney $(1972,1979)$ for the skull. Clade names defined by Joyce et al. (2004) are used throughout this study. The phylogeny proposed by Joyce (2007) is used as a guide for discussion. This new pattern of relationships partly results from the reinterpretation of the characters in the Early Jurassic turtle Kayentachelys aprix by Joyce (2007) and Sterli \& Joyce (2007), in contrast to Gaffney et al. (1987) and Gaffney \& Jenkins (in press). The recent discoveries in the Middle Jurassic, including Eileanchelys waldmani, appears to support the conclusions of Joyce (2007). Consequently, E. waldmani is here regarded as a stem turtle in agreement with the cladistic analyses of Anquetin et al. (2009) and Anquetin (2009). However, these phylogenetic considerations are inconsequential regarding the following morphological description.

The following species have been used as principal sources for comparison: Odontochelys semitestacea (Li et al. 2008); Proganochelys quenstedti (Gaffney 1990; personal observation of SMNS 15759, SMNS 16980, SMNS 17204 and MB R. 1854); Proterochersis robusta (Gaffney 1990; Karl \& Tichy 2000; personal observation of SMNS 16442, SMNS 16603, SMNS 17561, SMNS 17755, SMNS 17757 and SMNS 18440); Palaeochersis 

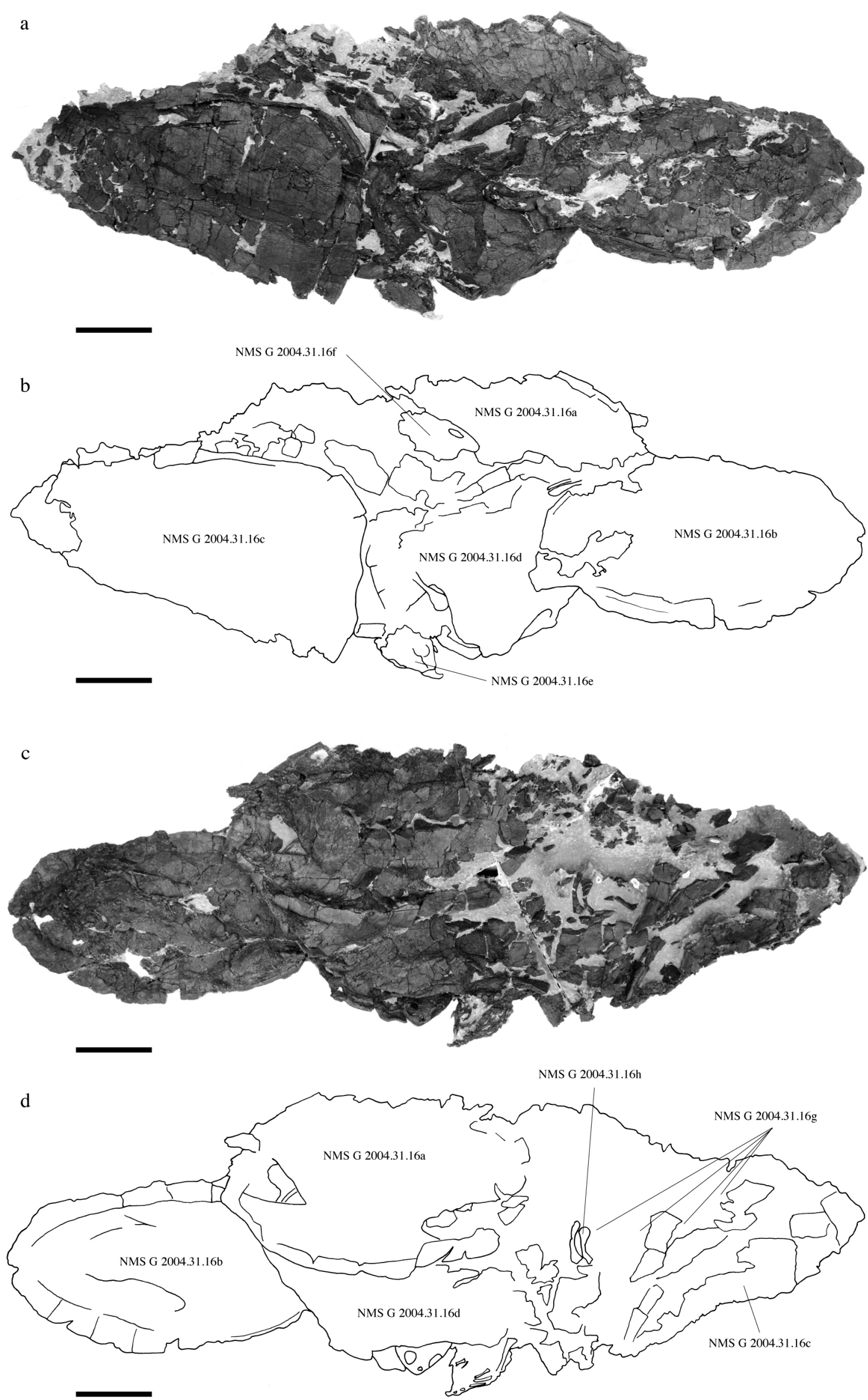

Figure 2 - Eileanchelys waldmani, NMS G 2004.31.16, position of the different specimens in the association. (a) upper side; (b) key to photograph in (a); (c) under side; (d) key to photograph in (c). Scale bars: $50 \mathrm{~mm}$. 
talampayensis (Rougier et al. 1995; Sterli et al. 2007); Australochelys africanus (Gaffney \& Kitching 1994, 1995; personal observation of BP/1/4933); Kayentachelys aprix (Gaffney et al. 1987; Sterli \& Joyce 2007; personal observation of MCZ 8917, MCZ 8988, MNA V1558, MNA V1563, MNA V2664, TMM 43651-1, TMM 43653-1 and TMM 43670-2); Indochelys spatulata (Datta et al. 2000); Heckerochelys romani (Sukhanov 2006); Condorchelys antiqua (Sterli 2008); Mongolochelys efremovi (Khosatzky 1997; Sukhanov 2000); Kallokibotion bajazidi (Gaffney \& Meylan 1992; personal observation of NHM R4918, NHM R4921 and NHM R4925); Meiolania platyceps (Gaffney 1983, 1996).

\section{Systematic palaeontology}

Testudinata Klein, 1760 (sensu Joyce et al. 2004)

Eileanchelys Anquetin, Barrett, Jones, Moore-Fay \& Evans, 2009

Type species. Eileanchelys waldmani Anquetin et al., 2009 , the only species in the genus.

Type locality. Same as species.

Diagnosis. Same as species.

Eileanchelys waldmani Anquetin, Barrett, Jones, MooreFay \& Evans, 2009

Holotype. NMS G 2004.31.15, the posterior half of a skull (Anquetin et al. 2009, fig. 1; Figs 3 and 4).

Paratypes. NMS G 2004.31.16a-f, an association comprising at least five and possibly six individuals in a single block (Figs 5-12): (a), a partial shell showing only a small part of the carapace, with the left side of the plastron missing, poorly preserved cervical vertebrae and a partial shoulder girdle; (b), a complete shell, with poorly preserved caudal vertebrae and a partial right hindlimb; (c), a nearly complete carapace missing only the posteriormost area and part of the left margin; (d), the anterior part of a shell and skull; (e), a fragmented skull consisting of the skull roof and part of the anterior palatal area (this skull may belong to the same individual as NMS G 2004.31.16c); (f), a complete crushed skull in lateral view that apparently does not belong to any individual in the association (see below).

Referred specimens. NMS G 1992.47.8 (Waldman collection), a block of matrix containing shell fragments, a partial pelvis and an incomplete hindlimb (femur, tibia and a fragment of fibula); NMS G 1992.47.37 (Evans \& Waldman collection), a small bridge peripheral; NMS G 1992.47.38 (Evans \& Waldman collection), an isolated fragment of costal plate; NMS G 1992.47.50 (Waldman collection), an anterior part of plastron with some carapace fragments; NMS G 1992.47.51 (Evans \& Waldman collection), an isolated left humerus; NMS G 2004.31.16g, a series of seven more or less complete cervical vertebrae; NMS G 2004.31.16h, a partial forelimb with the ulna, radius and possibly the distal part of the humerus; NMS G 2004.31.17, an isolated left pubis; NMS $\mathrm{G}$ 2004.31.18, an isolated row of bridge peripherals.

Locality and horizon. Cladach a'Ghlinne, Strathaird Peninsula, Isle of Skye, Scotland (Fig. 1). Cladach a'Ghlinne represents the best exposure of the Kilmaluag Formation, which is of late Bathonian age (Harris \& Hudson 1980; Andrews 1985).

Emended diagnosis. Relatively small turtle (carapace length of approximately $200-300 \mathrm{~mm}$, although it may have been bigger; see section 7.1) characterised by the following list of features: presence of nasals; elongated postorbital skull (compared to that of more basal forms); absence of flooring of the cavum acustico-jugulare; processus interfenestralis of the opisthotic more slender than that of more basal forms (e.g., Proganochelys quenstedti, Kayentachelys aprix), but more robust than that of crown-group turtles; separate openings of the canalis cavernosus and canalis stapedio-temporalis within the cavum acustico-jugulare; reduced thickness of the basicranial floor comparable with that of crown-group turtles; well-developed antrum postoticum; flat and horizontal vomer that is free of contacts for most of its length except at its extremities and along a short suture with the prefrontal; absence of processus trochlearis oticum; posteroventrally open incisura columellae auris; at least eight neurals (an additional plate between neural 8 and suprapygal 1 may be a ninth neural or a supernumerary suprapygal), two broad suprapygals, and eight costals present; contact of suprapygal 1 with peripheral laterally (probably peripheral 10); pygal region bordered by the two last pairs of peripherals (probably the tenth and eleventh); absence of carapacial or plastral fontanelles in adult individuals; one short but broad cervical scale present; vertebral scales significantly wider than pleurals; vertebral 3-4 sulcus on neural 6; reduced cleithrum present on epiplastron; arrow-shaped entoplastron that does not separate the epiplastra anteriorly; one pair of mesoplastra that meet medially; one small pair of extragulars present; and an anal scale that does not reach the hypoplastron.

\section{Skull morphology (Figs 3-8)}

\subsection{Dermal roofing elements}

Nasal. Among extant turtles, nasals occur only in chelids (Pleurodira). However, this bone is more common in Mesozoic turtles (e.g., Gaffney 1979). When present, 

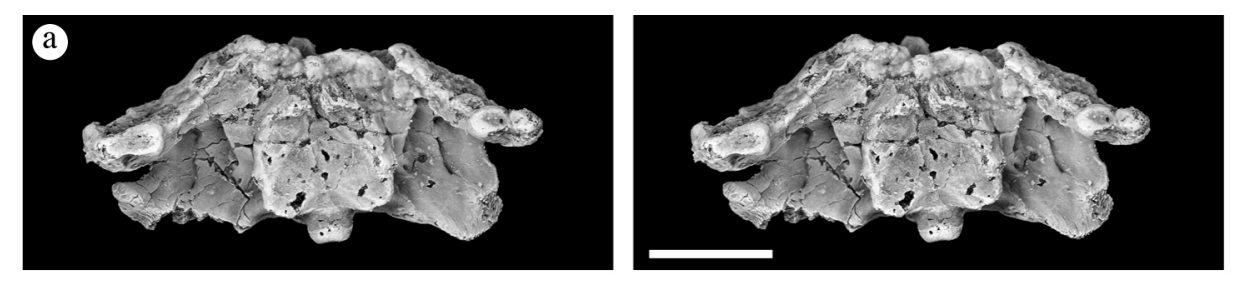

b
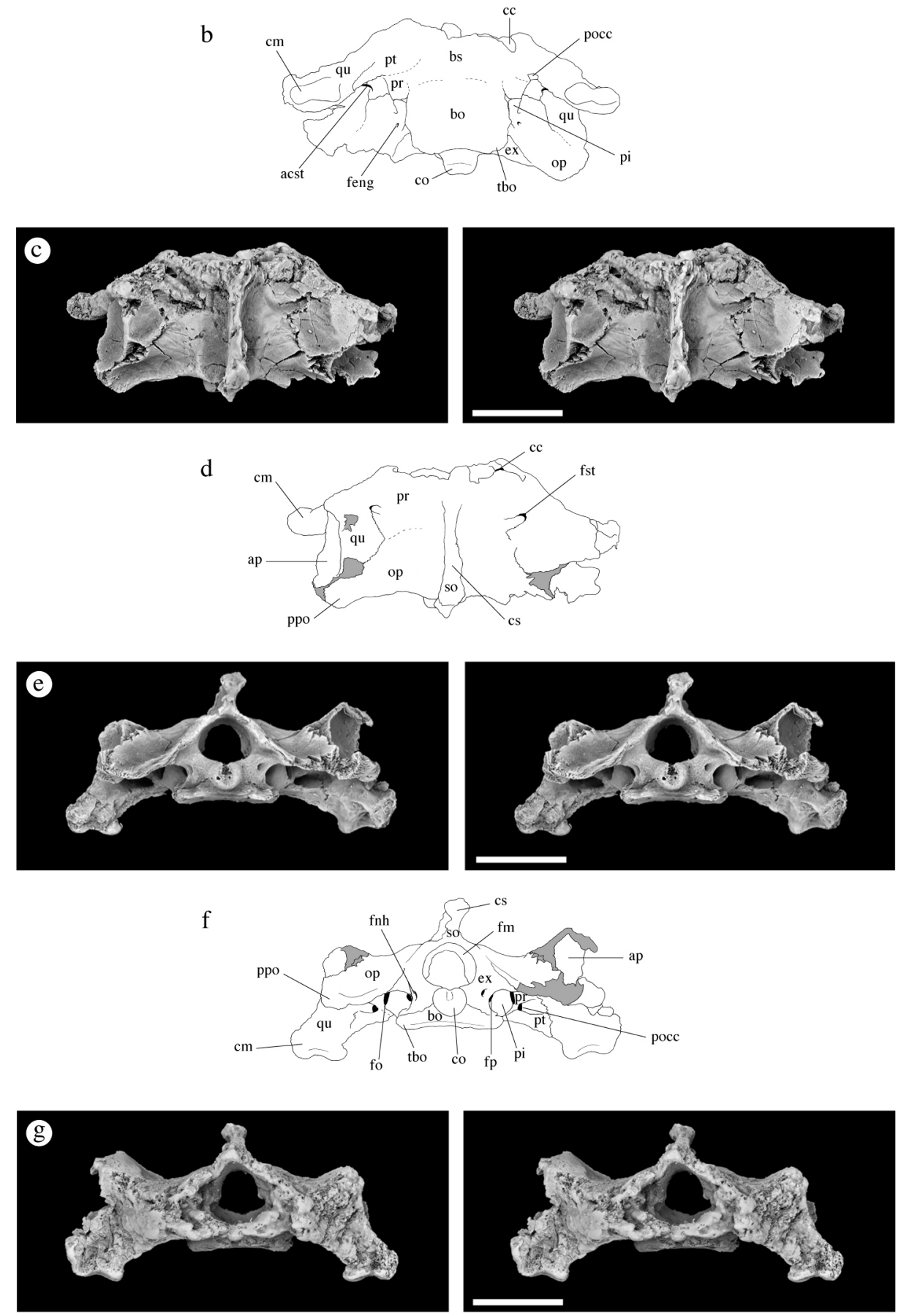

$\mathrm{h}$

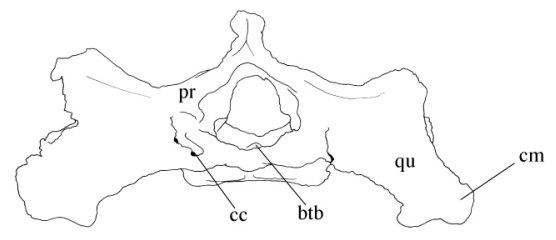


Figure 3 (previous page) - Eileanchelys waldmani, stereophotographs of the skull NMS G 2004.31.15 (holotype). (a, b) ventral view; (c, d) dorsal view; (e, f) posterior view; $(g, h)$ anterior view. Scale bars: $10 \mathrm{~mm}$. Abbreviations: acst, aditus canalis stapedio-temporalis; ap, antrum postoticum; bo, basioccipital; bs, basisphenoid; btb, basis tuberculi basalis; cc, canalis cavernosus; cm, condylus mandibularis; co, condylus occipitalis; cs, crista supraoccipitalis; ex, exoccipital; feng, foramen externum nervi glossopharyngei; fm, foramen magnum; fnh, foramen nervi hypoglossi; fo, fenestra ovalis; fp, fenestra perilymphatica; fst, foramen stapedio-temporale; op, opisthotic; pi, processus interfenestralis; pocc, posterior opening of canalis cavernosus; ppo, processus paroccipitalis of opisthotic; pr, prootic; pt, pterygoid; qu, quadrate; so, supraoccipital; tbo, tuberculum basioccipitale.

the nasals roof the fossa nasalis and form the dorsal margin of the apertura narium interna. The nasal is present in Eileanchelys waldmani and can be observed in NMS G 2004.31.16d (Fig. 5). The nasal can also be observed in NMS G 2004.31.16f, but the anterior tip of this skull is severely damaged and bone sutures are extremely difficult to distinguish (Fig. 7). In NMS G 2004.31.16d, the nasal is a rectangular element that contacts the other nasal along the midline for its entire length. The nasal also contacts the maxilla laterally, the prefrontal posterolaterally and the frontal posteriorly. As in Kayentachelys aprix Gaffney et al., 1987 (Sterli \& Joyce 2007, fig. 3), the posterior contact with the frontal is slightly concave, but the frontals do not separate the nasals in the midline as is the case in chelids and pleurosternids (Gaffney 1979; Joyce 2007). The nasal of Eileanchelys waldmani differs significantly from the large, elongate bone seen in Proganochelys quenstedti Baur, 1887 and Palaeochersis talampayensis Rougier et al., 1995 (Gaffney 1990; Sterli et al. 2007), and more closely resembles that of Kayentachelys aprix and basal pancryptodires. No specimen permits a ventral view of
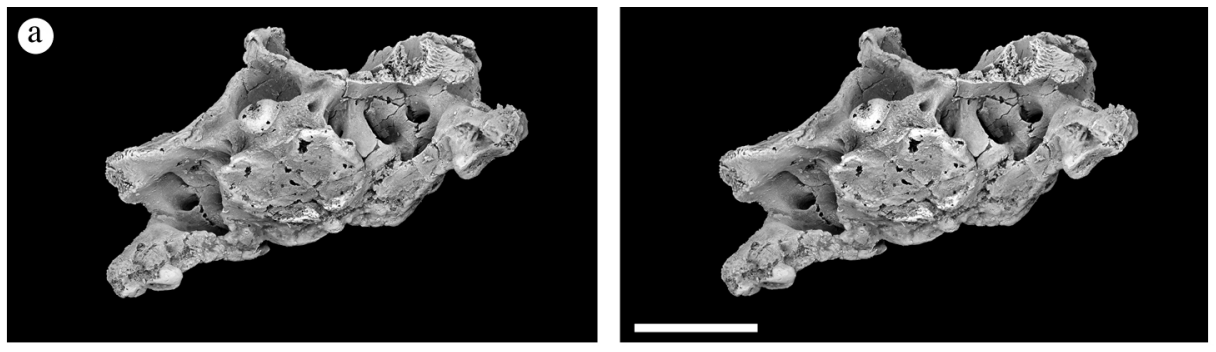

$\mathrm{b}$
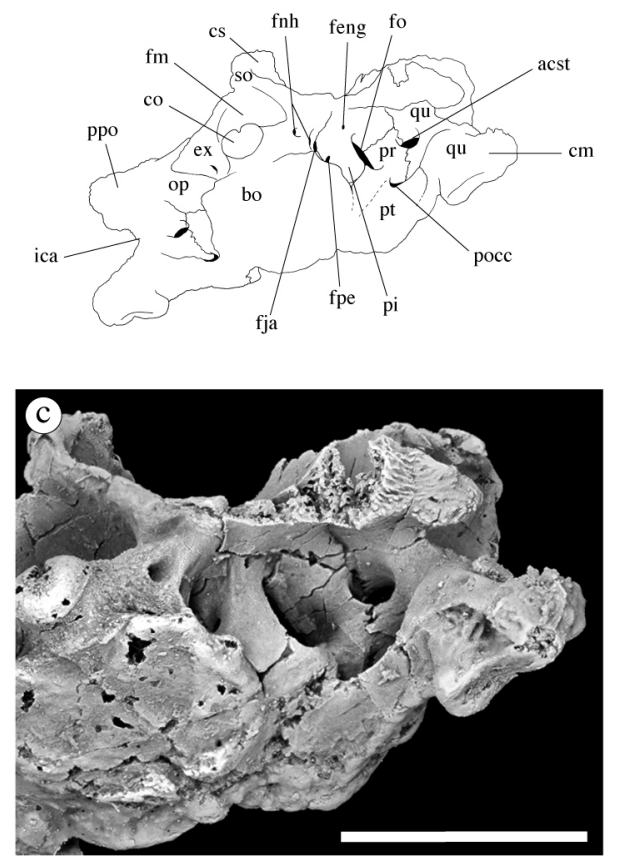

Figure 4 - Eileanchelys waldmani, NMS G 2004.31.15 (holotype). (a) stereophotographs of the cavum acustico-jugulare; (b) key to figure in (a); (c) close-up of the right cavum acustico-jugulare. Scale bar: $10 \mathrm{~mm}$. Abbreviations: acst, aditus canalis stapedio-temporalis; bo, basioccipital; cm, condylus mandibularis; co, condylus occipitalis; cs, crista supraoccipitalis; ex, exoccipital; feng, foramen externum nervi glossopharyngei; fm, foramen magnum; fja, foramen jugulare anterius; fnh, foramen nervi hypoglossi; fo, fenestra ovalis; fpe, fenestra perilymphatica; ica, incisura columellae auris; op, opisthotic; pi, processus interfenestralis; ppo, processus paroccipitalis of opisthotic; pocc, posterior opening of canalis cavernosus; pr, prootic; pt, pterygoid; qu, quadrate; so, supraoccipital. 

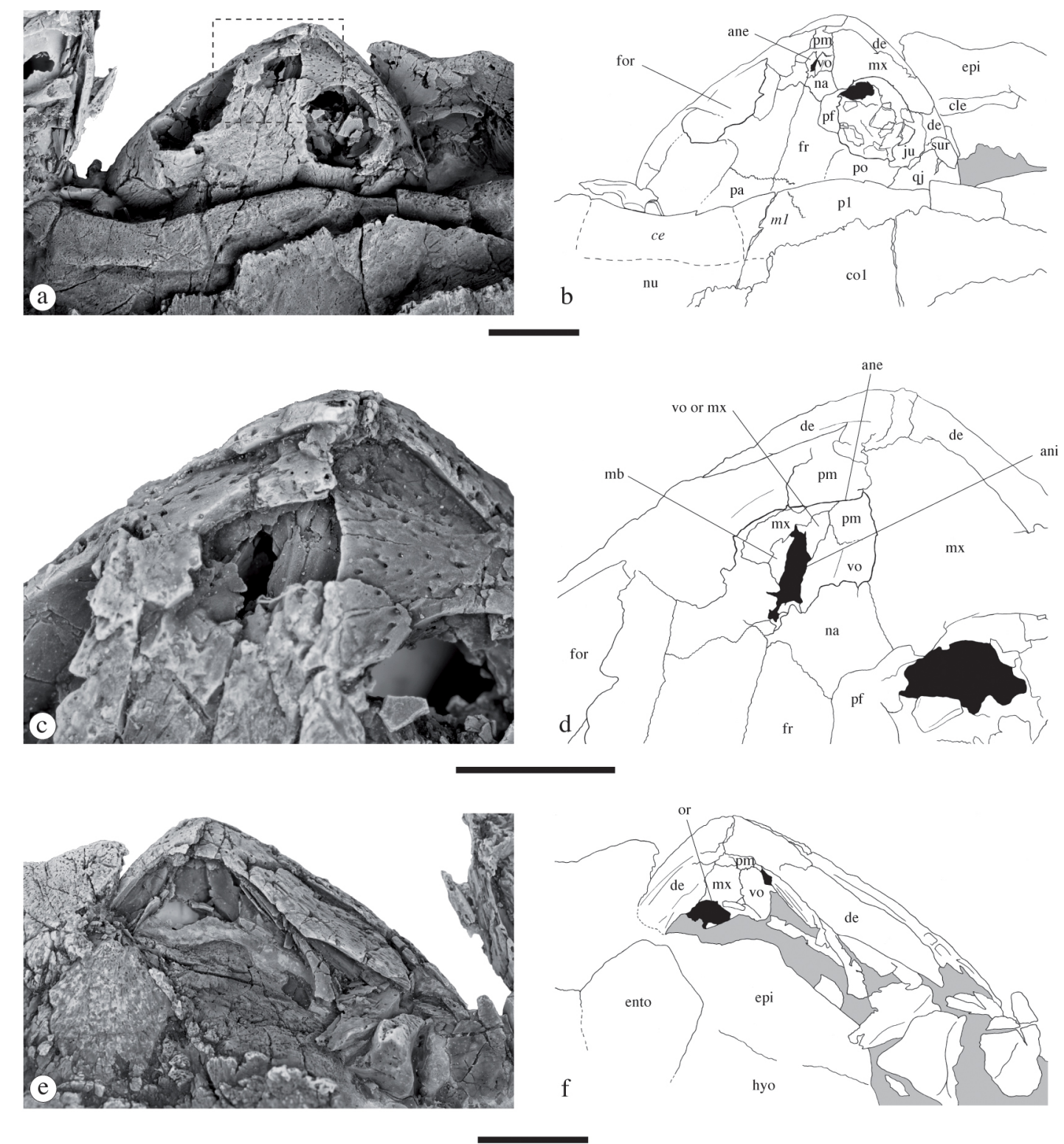

Figure 5 - Eileanchelys waldmani, NMS G 2004.31.16d (skull). (a, b) dorsal view; (c, d) close-up of the fossa nasalis area [shown in (a)]; $(e, f)$ ventral view. Scale bars: ( $a, b$ and e, f) $10 \mathrm{~mm}$; $(c, d) 5 \mathrm{~mm}$. Abbreviations: ane, apertura narium externa; ani, apertura narium interna; ce, cervical scale; cle, cleithrum; co, costal plate; de, dentary; epi, epiplastron; ento, entoplastron; for, fossa orbitalis; fr, frontal; hyo, hyoplastron; ju, jugal; m, marginal scale; mb, mandible; mx, maxilla; na, nasal; nu, nuchal plate; or, orbit; p, peripheral plate; pa, parietal; pf, prefrontal; pm, premaxilla; po, postorbital; qj, quadratojugal; sur, surangular; vo, vomer.

the nasal (i.e., the roof of the fossa nasalis), so it is unknown whether or not the nasal forms part of the sulcus olfactorius as in Proganochelys quenstedti and Kayentachelys aprix (Gaffney 1979, 1990; Sterli \& Joyce 2007).

Prefrontal. In turtles, the prefrontal usually contributes to some extent to the dorsal surface of the skull and presents a vertical descending process that forms the anterior wall of the fossa orbitalis. This descending process often contacts the palatine and vomer ventrally, although there are notable exceptions (e.g., Pleurodira and Trionychidae for the contact with the palatine: see Joyce 2007, p. 9). In those species without nasal bones, the prefrontals usually form the roof of the fossa nasalis and the dorsal margin of the apertura narium interna. In Eileanchelys waldmani, the prefrontals have a reduced exposure on the dorsal surface of the skull and they do not meet one another medially (NMS G 2004.31.16d, NMS G 2004.31.16e and NMS G 2004.31.16f; Figs 5-7). Dorsally, the prefrontal consists of a narrow rectangular lappet that forms the anterodorsal margin of the orbit. The prefrontal contacts the nasal anteromedially, the maxilla anteroventrally and the frontal medially and posteriorly. There is evidence that 

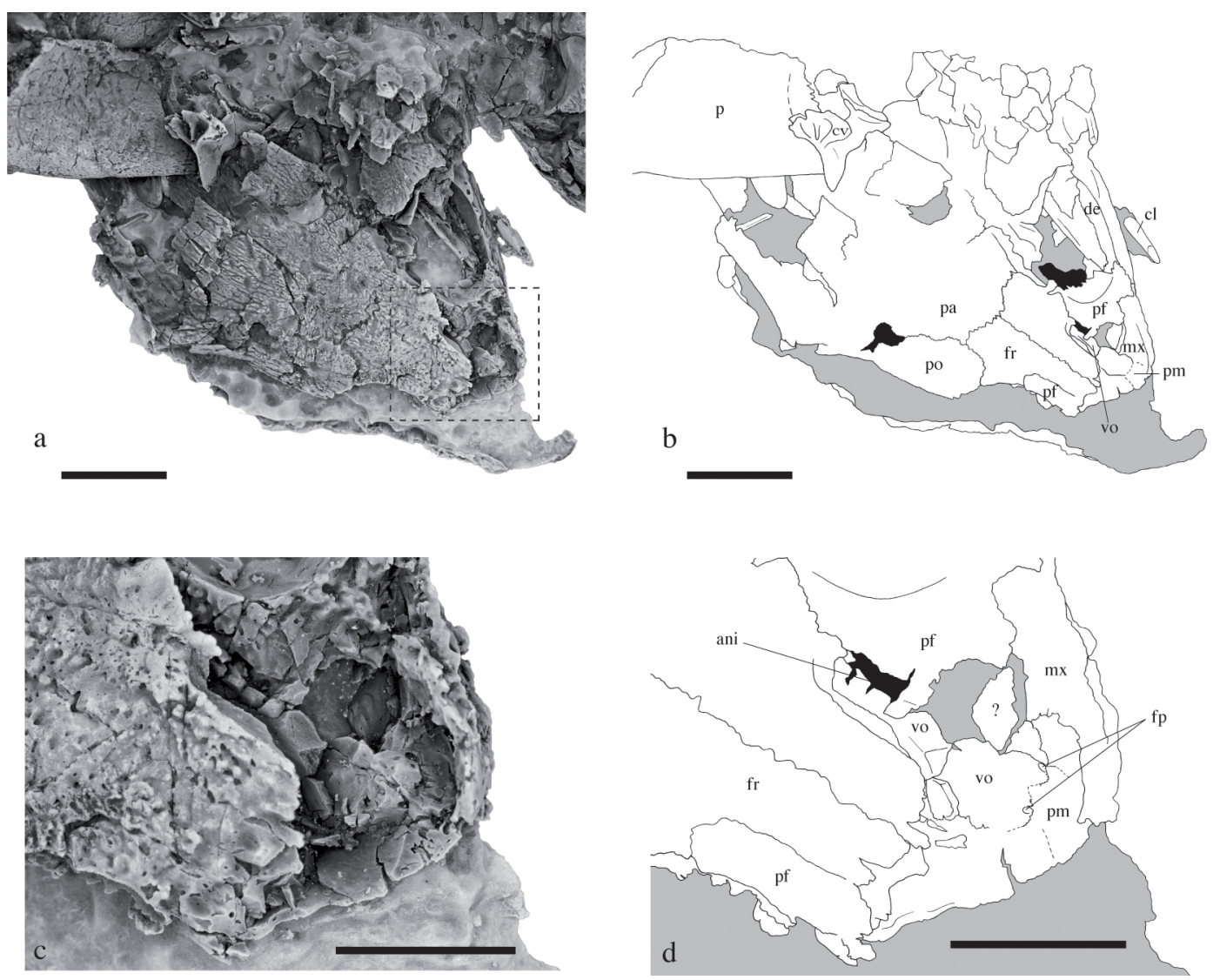

Figure 6 - Eileanchelys waldmani, NMS G 2004.31.16e. (a, b) dorsal view; (c, d) close-up of the snout area [shown in (a)]. Scale bars: (a, b) $10 \mathrm{~mm}$; (c, d) $5 \mathrm{~mm}$. Abbreviations: ani, apertura narium interna; cl, claw; cv, cervical vertebra; de, dentary; fp, foramen praepalatinum; $\mathrm{fr}$, frontal; mx, maxilla; p, peripheral plate; pa, parietal; pf, prefrontal; pm, premaxilla; po, postorbital; vo, vomer.

the descending process of the prefrontal contacts the vomer ventromedially (see Vomer, below), but it is unknown whether or not the prefrontal contacts the palatine on the floor of the fossa orbitalis. The development of the dorsal exposure of the prefrontal is variable within Testudinata (Joyce 2007, p. 10). In the most basal turtles (i.e., Proganochelys quenstedti and Palaeochersis talampayensis), the prefrontals are large elements that form a greater part of the interorbital skull roof, although these bones do not meet one another medially. The reduced prefrontal lappets of Eileanchelys waldmani are also found in the stem turtle Kayentachelys aprix, in paracryptodires, in some stem cryptodires and in chelids. In pelomedusoids and cryptodires (crown-group), the prefrontals are extended onto the dorsal surface of the skull and usually meet one another medially. This morphology might be associated with the loss or reduction of the nasal bones.

Lacrimal. The lacrimal bone is lost very early in turtle evolution and only the basalmost taxa are known to have one (i.e., Proganochelys quenstedti and Palaeochersis talampayensis). In Australochelys africanus Gaffney \& Kitching, 1994, there is a large foramen in the anteroventral part of the orbit, perhaps the lacrimal canal, but the preservation of the only known specimen is not good enough to have preserved bone sutures, so that it is unknown whether or not a lacrimal bone was present (BP/1/4933; Gaffney \& Kitching 1995). In NMS G 2004.31.16d (Fig. 5), this area is very well preserved and there is no lacrimal bone or foramen, as in Kayentachelys aprix and all more derived turtles (Joyce 2007; Sterli \& Joyce 2007).

Frontal. In Eileanchelys waldmani, the frontal is a large skull roof element that reaches the orbital margin laterally, preventing contact between the prefrontal and postorbital (NMS G 2004.31.16d, NMS G 2004.31.16e and NMS G 2004.31.16f; Figs 5-7). The frontal contacts the nasal anteriorly, the prefrontal anterolaterally, the postorbital posterolaterally, the parietal posteriorly and the other frontal medially. The anterior contact with the nasal is slightly convex (see Nasal, above), whereas the posterior contact with the parietal is straight and transverse. This morphology is identical to that of the vast majority of crown-group turtles and some stem turtles (i.e., Kayentachelys aprix and Kallokibotion bajazidi Nopcsa, 1923), whereas in other stem turtles (e.g., 

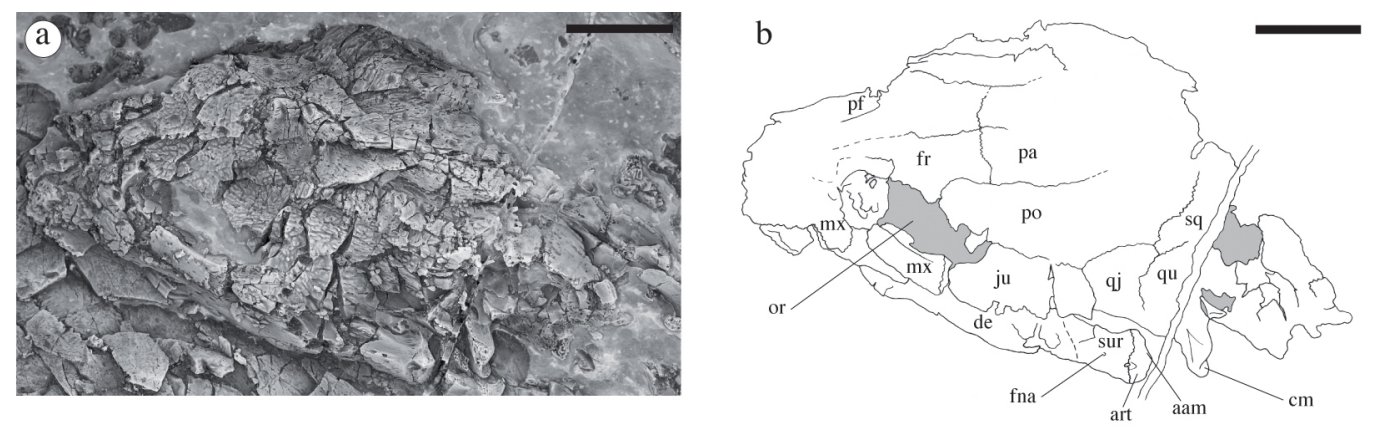

Figure 7 - Eileanchelys waldmani, NMS G 2004.31.16f. (a, b) dorsolateral view. Scale bars: 10 mm. Abbreviations: aam, area articularis mandibularis; art, articular; cm, condylus mandibularis; de, dentary; fna, foramen nervi auriculotemporalis; fr, frontal; ju, jugal; $\mathrm{mx}$, maxilla; or, orbit; pa, parietal; pf, prefrontal; po, postorbital; qj, quadratojugal; qu, quadrate; sq, squamosal; sur, surangular.

Proganochelys quenstedti, Palaeochersis talampayensis, Mongolochelys efremovi Khosatzky, 1997) the frontal is prevented from contacting the orbital margin by a prefrontal-postorbital contact (Joyce 2007, p. 11). The frontal of Eileanchelys waldmani greatly resembles that of Kayentachelys aprix, except for the posterolateral contact with the postorbital that is longer in the latter (MNA V1558). The anterior process of the frontal in Kallokibotion bajazidi is shorter than that of E. waldmani and its lateral participation in the orbital margin is smaller (Gaffney \& Meylan 1992, figs 4 and 6).

Parietal. In turtles, the parietal consists of two plates of bone: a dorsal horizontal plate forming much of the temporal skull roof and a parasagittal ventral plate that separates the anterior part of the cavum cranii from the fossa temporalis, the processus inferior parietalis (Gaffney 1979). The parietal can be observed partly in NMS G 2004.31.16d (Fig. 5), NMS G 2004.31.16e (Fig. 6) and NMS G 2004.31.16f (Fig. 7), but no specimen shows the processus inferior parietalis so that its development and the morphology of the foramen nervi trigemini area is unknown in Eileanchelys waldmani. The parietal is a long, quadrangular element that forms at least half of the length of the skull roof. It contacts the other parietal medially for its entire length, the frontal anteriorly and the postorbital laterally. NMS G 2004.31.16f (Fig. 7) shows that there is a posterolateral contact between the parietal and squamosal on the skull roof, which suggests the absence or weak development of an upper temporal emargination. The upper temporal emargination, if present, would not reach either the quadratojugal or the jugal. The posterior margin of the skull roof is not preserved in any specimens. The morphology of the parietal in Eileanchelys waldmani (i.e., an elongate parietal that makes up to half of the skull roof) is common in the vast majority of turtles that are more derived than Kayentachelys aprix, including Mongolochelys efremovi, Kallokibotion bajazidi and crown-group turtles. In the latter, the extent of the parietal on the skull roof may be secondarily reduced by the development of the upper temporal emargination, but even in these cases the parietal is still an elongate bone. In contrast, more basal turtles like Proganochelys quenstedti and Palaeochersis talampayensis have a comparatively smaller parietal that is wider than long. A similar morphology is known in Meiolania platyceps Owen, 1886, a stem turtle from the Pleistocene of Australia (Gaffney 1983), but in that case it is obviously a secondarily derived morphology that is probably related to the peculiar horned skull of this species (Joyce 2007). Kayentachelys aprix presents an intermediate morphology of the parietal (Sterli \& Joyce 2007, fig. 3): it is larger and more elongate than in the basalmost taxa, but not as much as in more derived forms like Eileanchelys waldmani, Kallokibotion bajazidi, Mongolochelys efremovi and crown-group turtles.

Jugal. In turtles, the jugal is one of the main elements of the cheek area. Usually, it forms part of the orbital margin and presents a medial process anteriorly that contacts the pterygoid and/or the palatine (Gaffney 1979). The jugal can be observed in NMS G 2004.31.16f (Fig. 7) and also, but only partly, in NMS G 2004.31.16d (Fig. 5). The jugal is an elongate quadrangular element that forms a great part of the zygomatic area. It is exposed for its entire length along the ventral cheek margin, which does not present any evidence of lower temporal emargination. The jugal contacts the maxilla anteriorly below the orbit, the postorbital dorsally and the quadratojugal posteriorly. The medial process of the jugal contacts what appears to be the palatine in the floor of the left fossa orbitalis of NMS G 2004.31.16d, but no further observation of the jugal internal morphology can be made. The jugal-postorbital suture is sub-horizontal and enters the orbital margin approximately halfway up the orbit. The posterior contact with the quadratojugal (only preserved in NMS G 2004.31.16f) may have been slightly concave (Fig. 7). The suture between the maxilla and jugal is more or less vertical. It is remarkable that this suture is situated below the orbit, so that the jugal not 
only forms part of the posterior margin of the orbit as in most turtles but also part of its ventral margin. This morphology is common to all stem turtles in which this area of the skull is known, whereas it is uncommon in crown-group turtles where the jugal is entirely posterior to the orbit and only forms part of its posterior margin (with the exception of marine turtles and some pleurodires).

Quadratojugal. The quadratojugal is lost or greatly reduced in those turtles with an extensive lower temporal emargination (Gaffney 1979). In Eileanchelys waldmani, there is no cheek emargination and the quadratojugal is well developed (only visible in NMS G 2004.31.16f; Fig. 7). It is a quadrangular element that is higher than long. It contacts the jugal anteriorly, the postorbital dorsally, the squamosal posterodorsally and the quadrate posteriorly. The contact with the jugal may have been slightly convex. Posteriorly, the quadratojugal has a concave, C-shaped suture with the quadrate that is typical of most turtles. However, the quadratojugal does not appear to participate in the formation of the cavum tympani. The dorsal contact with the postorbital may have been slightly convex, although the skull NMS G 2004.31.16f is severely damaged in this area (Fig. 7). In the same way, the quadratojugal-squamosal suture appears to be very short but the poor preservation of the remains prevents any definitive conclusion.

Squamosal. The squamosal is usually well developed in turtles. It lies posterodorsal to the cavum tympani on each side of the skull and forms a large portion of the antrum postoticum. The morphology of the squamosal is mostly unknown in Eileanchelys waldmani. NMS G 2004.31.16f is the only specimen where a part of the squamosal is preserved, which consists only of a fragment of the anterior part of the bone (Fig. 7). It shows that the squamosal contacts the quadrate lateroventrally, the quadratojugal anteroventrally, the postorbital anteriorly and the parietal medially. Although the squamosal is missing in NMS G 2004.31.15, its sutures with the opisthotic and quadrate are partly preserved (Fig. 3c, d). These sutures indicate that an antrum postoticum was present and that it was formed, at least posteriorly, by the squamosal. The exact shape and extent of the antrum postoticum is unknown in Eileanchelys waldmani, but by comparison it seems to be deeper than that of Kayentachelys aprix (MCZ 8917, TMM 43653-1 and TMM 43670-2).

Postorbital. The postorbital has a great size range among turtles (Gaffney 1979), but is generally welldeveloped in basal forms (i.e., stem turtles and stem cryptodires). Indeed, in Eileanchelys waldmani, the postorbital is a greatly elongate bone that contacts the frontal anteromedially, the jugal anteroventrally, the quadratojugal posteroventrally, the squamosal posteriorly and the parietal dorsally. The postorbital is almost entirely preserved in NMS G 2004.31.16f (Fig. 7), although it is severely damaged, whereas only the anteriormost part is preserved in NMS G 2004.31.16d (Fig. 5) and NMS G 2004.31.16e (Fig. 6). As in most turtles, the postorbital forms the posterodorsal margin of the orbit. There is no trace of a descending process that would contact the palatine and form a posterior wall to the orbit, in contrast to pleurodires. Compared to more basal forms, Eileanchelys waldmani is characterised by an expanded postorbital skull length. In accordance with this observation, the postorbital of $E$. waldmani is significantly elongated compared to that of Proganochelys quenstedti, Palaeochersis talampayensis and Kayentachelys aprix.

Supratemporal. Currently, only the basalmost turtles Proganochelys quenstedti, Palaeochersis talampayensis and Odontochelys semitestacea Li et al., 2008 are known to possess a supratemporal, which is intercalated between the parietal and squamosal on the posterior margin of the skull roof. Due to poor preservation, it is unclear whether or not Australochelys africanus had a supratemporal (BP/1/4933; Gaffney \& Kitching 1995). Similarly, this area of the skull is damaged in all available specimens of Kayentachelys aprix (Sterli \& Joyce 2007, p. 680 ) and Eileanchelys waldmani, so that it is not possible to determine the presence or absence of this element in these taxa. However, all more derived taxa lack a

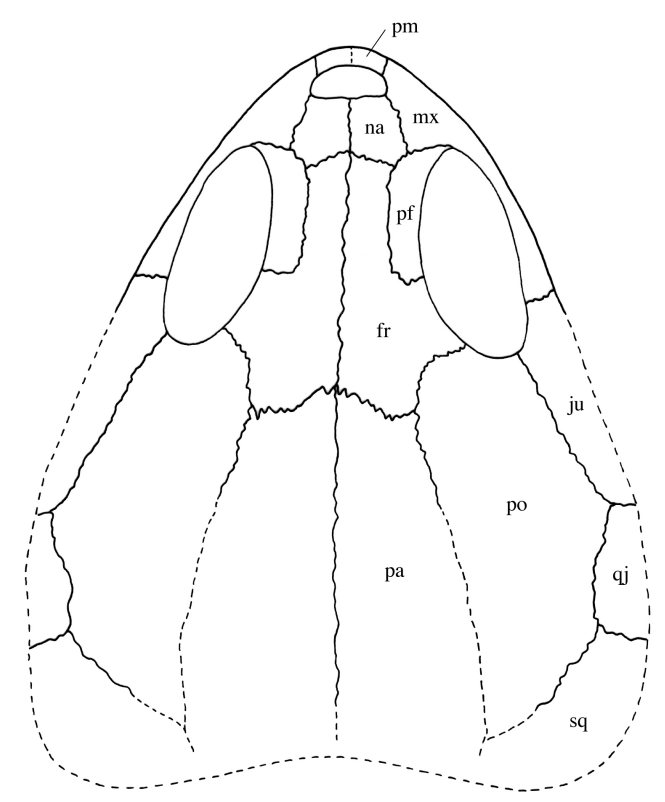

Figure 8 - Tentative reconstruction of the skull of Eileanchelys waldmani in dorsal view. Abbreviations: fr, frontal; ju, jugal; mx, maxilla; na, nasal; pa, parietal; pf, prefrontal; pm, premaxilla; po, postorbital; qj, quadratojugal; sq, squamosal. 
supratemporal (Joyce 2007). With respect to the phylogenetic position of Kayentachelys aprix and Eileanchelys waldmani (Joyce 2007; Anquetin et al. 2009), the absence of the supratemporal in these taxa, though probable, needs to be confirmed.

A tentative reconstruction of the skull of Eileanchelys waldmani in dorsal aspect is provided in Figure 8.

\subsection{Palatal elements}

Premaxilla. In the majority of turtles, the premaxillae are paired elements that floor the fossa nasalis and form the ventral margin of the apertura narium externa and the anterior tip of the triturating surface. The premaxilla can be observed only in NMS G 2004.31.16d (Fig. 5). It contacts the maxilla laterally and the vomer posteriorly on the floor of the fossa nasalis (see Vomer, below). Because of the relatively poor preservation of this area in NMS G 2004.31.16d, it is unclear whether the premaxillae are paired or fused, and whether or not foramina praepalatinum are present. However, the foramina praepalatinum are preserved in NMS G 2004.31.16e and located between the vomer and premaxilla close to the suture with the maxilla (Fig. 6). The palatal surface of the premaxilla is covered by the dentaries in NMS G 2004.31.16d, so that its contribution to the triturating surface is unknown. In most tetrapods, the premaxillae send a dorsal medial process that separates the external nares into two openings. This plesiomorphic condition is present in Proganochelys quenstedti, Palaeochersis talampayensis, Odontochelys semitestacea, and probably also in Australochelys africanus. The Late Cretaceous Kallokibotion bajazidi and Pleistocene Meiolania platyceps also have an apertura narium externa divided into two openings, but the condition in these taxa does not appear to be homologous with the plesiomorphic tetrapod feature (Gaffney 1983; Gaffney \& Meylan 1992; Joyce 2007). All other turtles, including Kayentachelys aprix and Eileanchelys waldmani, have an undivided apertura narium externa.

Maxilla. In turtles, the maxilla usually consists of three processes (Gaffney 1979). The alveolar process, which consists of the labial ridge, is a thin, sharp blade enclosed on both sides by the rhamphotheca (the horny beak). The palatine process is a horizontal plate that extends medially flooring the fossa orbitalis and meets the palatal bones (e.g., palatine, vomer, pterygoid). On the ventral surface of the palatine process a triturating surface is usually developed and is covered in life by the rhamphotheca. Finally, the prefrontal process is an anterodorsal extension of the maxilla that forms the lateral margin of the apertura narium externa, the lateral wall of the fossa nasalis and the anterior and ventral parts of the orbital margin and/or the anterior wall of the fossa orbitalis. In Eileanchelys waldmani, all three paratype skulls show at least part of the maxilla (Figs 5-7). However, no specimen shows a ventral view of this bone, so that the triturating surface cannot be described. The maxilla contacts the jugal posteriorly, the prefrontal dorsally and medially, the nasal anterodorsally and the premaxilla anteriorly. Within the fossa orbitalis, it is apparent that the maxilla contacts the palatine medially (NMS G 2004.31.16d). A posteromedial contact with the pterygoid (found in most turtles) cannot be confirmed as this area is not preserved in any specimen. A minute but definite contact between the maxilla and vomer can be observed on the floor of the fossa nasalis lateral to the premaxilla-vomer suture (NMS G 2004.31.16d; Fig. 5c, d; see Vomer, below). As in most turtles, the maxilla forms the lateral wall of the fossa nasalis as well as the anterior and anteroventral margins of the orbit. The foramen orbito-nasale is not preserved in any specimen.

Vomer. The contacts of the vomer with the other palatal bones are highly variable within turtles and the morphology of this bone has greatly changed between stem turtles and the crown-group. Eileanchelys waldmani offers a unique opportunity to understand the evolution of this feature (see Discussion, below). The vomer can be observed in NMS G 2004.31.16d (Fig. 5) and NMS G 2004.31.16e (Fig. 6). In the former, the anterior half of the vomer can be seen in ventral and dorsal (within the fossa nasalis) view, whereas in the latter specimen the vomer is only partly apparent in dorsal view. No specimen shows the posterior part of this bone. In Eileanchelys waldmani, the vomer is a narrow and elongate unpaired bone. The plesiomorphic condition found in most tetrapods, as well as Proganochelys quenstedti, Palaeochersis talampayensis, and also probably Australochelys africanus (Gaffney \& Kitching 1995; BP/1/4933), consists of paired vomers. In all more derived turtles (including Kayentachelys aprix, Eileanchelys waldmani and Heckerochelys romani), the vomers are fused into a single element. In contrast to most turtles, but similar to the condition that is found in Proganochelys quenstedti, Australochelys africanus, Palaeochersis talampayensis, Kayentachelys aprix and Heckerochelys romani, the vomer is a flat element that lacks a medial septum dividing the apertura narium interna ventrally. However, it is planar (i.e., not curved), differing from the dorsally convex element seen in Proganochelys quenstedti (SMNS 16980) and Australochelys africanus (BP/1/4933). Sukhanov (2006, p. 113) described a "more or less horizontal" vomer in Heckerochelys romani. This might correspond to the morphology in Eileanchelys waldmani, but there is no illustration of the vomer of $H$. romani (Sukhanov 2006) so that it is difficult to extend the comparison to this taxon. There is no evidence of 
vomerine teeth, which currently are known with confidence only in Proganochelys quenstedti and Odontochelys semitestacea (Gaffney 1990; Li et al. 2008). Anteriorly, the vomer contacts the premaxilla on the floor of the fossa nasalis and paired foramina praepalatinum are present between these two bones (Figs 5, 6). Although the exact limits of each bone in this area are slightly uncertain, there is a definite contact between the vomer and maxilla lateral to the premaxilla-vomer suture (NMS G 2004.31.16d; Fig. 5c, d).

The contact with the maxilla is one of the most consistent contacts of the vomer in turtles (Gaffney 1979). Usually, the maxilla meets the vomer twice: firstly anterodorsally along the anterolateral portion of the vomer on the floor of the fossa nasalis, and secondly posteroventrally at the level of the ventral expansion of the vomer on the triturating surface, which forms an incipient secondary palate. This corresponds to the derived vomerine morphology found in most turtles (i.e., Meiolania platyceps, Mongolochelys efremovi, Kallokibotion bajazidi, and more derived taxa that possess a vomer): the vomer consists of an anterodorsal and a posteroventral portion expanded horizontally and connected by a sagittal septum dividing the meatus choanae (the "dumbbell shape" of Gaffney 1979). As illustrated by Proganochelys quenstedti and Eileanchelys waldmani, in basalmost turtles the vomer is a flat element that lacks a ventral septum and that contacts the maxilla only for a short distance anterolaterally.

Posterior to its anterior contacts with the premaxilla and maxilla, the vomer is exposed and forms the medial margin of the apertura narium interna (NMS G 2004.31.16d; Fig. 5c, d). At the level of the anterior wall of the orbit, the vomer has a small dorsal suture with the descending process of the prefrontal and they both define the ventral margin of the fissura ethmoidalis (NMS G 2004.31.16d and NMS G 2004.31.16e; see Fig. 6c, d). Posterior to this contact, the vomer is still exposed laterally for at least a short distance, but the posterior part of this bone is not preserved in any specimen, so that the posterior contacts of the vomer with the palatine and pterygoid are uncertain. In all turtles more derived than Kayentachelys aprix and Eileanchelys waldmani, the vomer is entirely framed laterally by the maxilla and the palatine. In contrast, Proganochelys quenstedti, Palaeochersis talampayensis and Australochelys africanus have a vomer that is exposed laterally for most of its length and that does not meet the descending process of the prefrontal (due to poor preservation, the latter feature is unclear for Palaeochersis talampayensis and Australochelys africanus; BP/1/4933; Sterli et al. 2007). Currently, Eileanchelys waldmani is the most basal turtle to show a prefrontal-vomer contact. Sterli \& Joyce (2007, p.
680) tentatively proposed that a prefrontal-vomer contact was also present in Kayentachelys aprix, but personal observation of MCZ 8917 and MNA V1558 (the holotype of $K$. aprix) suggests that the contact between the prefrontal and vomer is not preserved in either specimens, so that the conclusion of Sterli \& Joyce (2007) may not be accurate.

Palatine. The palatine is not visible in any specimen of Eileanchelys waldmani, with the exception of a fragment on the floor of the left fossa orbitalis of NMS G 2004.31.16d (Fig. 5a, b). This fragment of palatine contacts the jugal posterolaterally and the maxilla laterally. The foramen orbito-nasale and the foramen palatinum posterius are not preserved in any specimen. Sterli \& Joyce (2007, p. 680) state that there is no contact between the palatine and jugal in Kayentachelys aprix. However, as illustrated by Gaffney (1990) in Proganochelys quenstedti, the jugal often overlaps the maxilla dorsally and contacts the palatine in the floor of the fossa orbitalis in turtles, whereas this contact is covered ventrally by a posterior extension of the maxilla that contacts the pterygoid. A jugal-palatine contact is indeed present in the floor of the fossa orbitalis of Kayentachelys aprix (MCZ 8917).

\subsection{Palatoquadrate elements}

Quadrate. The quadrate is a major bone in the turtle skull as it participates in the formation of several important structures: the mandibular articulation, the middle ear (which is highly specialised in turtles), and the enclosed cranioquadrate space (the area between the palatoquadrate elements and the primary neurocranium). No complete quadrate is known for Eileanchelys waldmani, but most of this bone can be seen in NMS G 2004.31.15 (Figs 3, 4) and a partial quadrate is present in NMS G 2004.31.16f (Fig. 7). The quadrate contacts the pterygoid anteromedially, along the anterior wall of the cavum acustico-jugulare, the squamosal laterodorsally, the quadratojugal anteriorly, as well as the prootic anteromedially and the opisthotic posteromedially (both in the roof of the cavum acusticojugulare and in the floor of the fossa temporalis superior). Laterally the quadrate forms a well-developed cavum tympani and the posterodorsal portion of the cavum indicates the presence of an antrum postoticum (NMS G 2004.31.15; Fig. 3e, f). However, as the squamosal is missing in NMS G 2004.31.15, the exact posterior development of the antrum postoticum is unknown. The incisura collumellae auris is widely open posteroventrally. The condylus mandibularis consists of two facets separated by an anteroposterior groove. The medial facet is slightly concave and appears to extend further ventrally 
than the lateral facet. Dorsomedial to the processus articularis, the quadrate sends a vertical pterygoid process that covers the quadrate process of the pterygoid anteriorly. As in all turtles, these two processes form the anterior wall of the cavum acustico-jugulare and the posterior wall of the fossa temporalis inferior. Due to poor preservation of the relevant area, the medial extent of the pterygoid process of the quadrate is unclear.

In the floor of the fossa temporalis superior (i.e., on the dorsal part of what could be called the otic chamber), the quadrate forms the lateral half of the foramen stapedio-temporale, the medial half being formed by the prootic. There is no obvious trace of a processus trochlearis oticum on the anterodorsal slope of the otic chamber. The aditus canalis stapedio-temporalis and the posterior opening of the canalis cavernovus open along the quadrate-prootic suture in the roof of the cavum acustico-jugulare, so that the quadrate forms their lateral half. It is noteworthy that in Eileanchelys waldmani these openings are situated far apart within the cavum acustico-jugulare, with the aditus canalis stapediotemporalis opening at the level of the anterior wall of the fenestra ovalis, whereas they are often closer or even associated (the aditus canalis stapedio-temporalis opening in the roof of the canalis cavernosus) in more derived species, with the aditus canalis stapediotemporalis opening anterior to the fenestra ovalis. A similar morphology occurs in Kayentachelys aprix (MCZ 8917) and maybe also in Australochelys africanus (BP/ 1/4933).

Pterygoid. The pterygoid plays an important role in the early evolution of the turtle skull and in the differentiation of pleurodires and cryptodires, although this last point is not completely elucidated. In turtles, the pterygoid can be described as a triradiate plate of bone with an anterior palatine process, a lateral transverse process and a posterolateral quadrate ramus (Gaffney 1990). Only the posterior part of the pterygoid is preserved in the available material of Eileanchelys waldmani. Ancestrally, the tetrapod skull is kinetic, with two movable joints between the braincase and palatoquadrate elements. Proganochelys quenstedti and Odontochelys semitestacea retain one of these kinetic joints (Gaffney 1990; Li et al. 2008): the basipterygoid articulation (the cranioquadrate space is open and the pterygoid articulates with the basisphenoid). All other turtles possess an akinetic skull: the cranioquadrate space is closed by a sutural contact between the pterygoid and basisphenoid. The closing of the cranioquadrate space in turtles implies the formation of specific structures for the passage of nerves and arteries. For example, the lateral head vein (vena capitis lateralis), which passes through the cranioquadrate space in other reptiles, lies on the dorsal surface of the pterygoid in a trough, the sulcus cavernosus. This sulcus may be roofed posteriorly, notably by the quadrate and prootic, forming the canalis cavernosus. The posterior extent of the pterygoid is highly variable among turtles. In stem turtles and in panpleurodires, the posterior extent of the pterygoid is usually limited. In contrast, the pterygoid extends posteriorly between the basisphenoid and quadrate for an extensive length and even contacts the basioccipital in numerous pancryptodires. In this case, the pterygoid floors the cavum acustico-jugulare and even forms a great part of the canalis caroticus internus in eucryptodires.

The pterygoid of Eileanchelys waldmani can only be observed in NMS G 2004.31.15 (Fig. 3a, b). The pterygoid of this specimen is broken just posterior to the hypothetical level of the basipterygoid processes, which are small lateral processes of the basisphenoid that contributed to the former basipterygoid articulation and that are found in Kayentachelys aprix, Heckerochelys romani and Condorchelys antiqua, despite the fusion of the basipterygoid articulation. Consequently, the presence or absence of these basipterygoid processes, of pterygoid teeth (found in $K$. aprix) and of an interpterygoid vacuity (found in $K$. aprix, $H$. romani and $C$. antiqua) remain conjectural in Eileanchelys waldmani. As preserved in NMS G 2004.31.15, the pterygoid contacts the quadrate posterolaterally, the prootic posteriorly and the basisphenoid medially. Posteriorly, the pterygoid does not reach the basioccipital. A canalis cavernosus is present and is entirely floored by the pterygoid. However, the posterior extent of the pterygoid is relatively short and there is no flooring of the cavum acustico-jugulare, neither by the pterygoid as in pancryptodires nor by the quadrate and/or prootic as in most panpleurodires. A similar morphology (i.e., a pterygoid that floors a canalis cavernosus but does not floor the cavum acusticojugulare) is known in Kayentachelys aprix, Heckerochelys romani and Condorchelys antiqua (Sukhanov 2006; Sterli \& Joyce 2007; Sterli 2008). The posterior extent of the pterygoid (or the location of the posterior opening of the canalis cavernosus) is similar in Eileanchelys waldmani and in Heckerochelys romani. This posterior extent is less pronounced in Kayentachelys aprix, but more pronounced in Condorchelys antiqua, which could suggest a transformation series. More evidence is needed to test this hypothesis. As a result of the posterior extent of the pterygoid in Eileanchelys waldmani, the posterior opening of the canalis nervi facialis is located in the roof of the canalis cavernosus, whereas in Kayentachelys aprix it is located outside of the canalis cavernosus in the roof of the cavum acustico-jugulare (Sterli \& Joyce 2007, fig. 5D). 


\subsection{Braincase elements}

Supraoccipital. In turtles, the supraoccipital forms the posterior part of the cavum cranii and is characterised by the development of a dorsal, vertical crest, the crista supraoccipitalis, which separates the posterior portion of the fossae temporalis superior medially. The crista supraoccipitalis is very poorly developed in Proganochelys quenstedti, whereas it is fully developed in more derived forms and sometimes extends posteriorly far beyond the occipital region, creating an additional attachment site for the jaw musculature (Gaffney 1979; Joyce 2007). Concerning Eileanchelys waldmani, the supraoccipital can only be observed in NMS G 2004.31.15 (Fig. 3), but its contacts are difficult to establish. As in most turtles (Gaffney 1979), the supraoccipital seems to contact the exoccipital posteroventrally, the opisthotic posterolaterally, the prootic anterolaterally and the parietal anteriorly. In both dorsolateral margins of the foramen magnum, the suture between the supraoccipital and the exoccipital is clearly visible. The sutures of the supraoccipital with the opisthotic and prootic are either fused or not preserved in NMS G 2004.31.15. In dorsal view, the supraoccipital-opisthotic contact might be represented by a light wrinkle that curves medially from the point where the supraoccipital-exoccipital suture meets the opisthotic to the area located just posteromedial to the groove marking the passage of the stapedial artery. As in most turtles, the supraoccipital forms the dorsal margin of the foramen magnum. Internally, the supraoccipital also forms the dorsal margin of the hiatus acusticus, the opening between the cavum cranii and the cavum labyrinthicum. There is a welldeveloped crista supraoccipitalis, but the total height of this structure is unknown as the temporal skull roof is missing. The part of the crista supraoccipitalis positioned just above the foramen magnum shows a sub-vertical margin that faces posteriorly, which could indicate that the crista supraoccipitalis did not extend posteriorly much beyond the level of the foramen magnum.

Exoccipital. In turtles, the exoccipitals lie lateral to the foramen magnum and usually form part of the condylus occipitalis, although this is variable. The exoccipital can only be seen in NMS G 2004.31.15 (Figs 3e, f and 4). It contacts the supraoccipital dorsally, the opisthotic laterally and anteriorly, and the basioccipital ventrally. There is no medial contact of the exoccipitals, either dorsal or ventral to the foramen magnum. The basioccipital-exoccipital suture can be followed up to the base of the condylus occipitalis then it appears to be fused, hence the exoccipital probably forms part of the condyle but it is unclear how much it contributes. Posteroventrally, the exoccipital also participates in the formation of the tuberculum basioccipitale (see Basioccipital, below). As in Proganochelys quenstedti, Palaeochersis talampayensis, Australochelys africanus, Heckerochelys romani and Condorchelys antiqua, there is no foramen jugulare posterius, and consequently no proper recessus scalae tympani, but a foramen jugulare intermedium (sensu Sterli \& Joyce 2007, p. 685). The exoccipital forms the posteromedial and ventral margins of the foramen jugulare intermedium, as well as the posterior half of the foramen jugulare anterius and the ventromedial margin of the fenestra perilymphatica (see Opisthotic, below). In NMS G 2004.31.15, each exoccipital is pierced by two foramina nervi hypoglossi, the anterior one opening in the margin of the foramen jugulare intermedium. The exoccipital forms the lateral and ventrolateral margins of the foramen magnum, which is approximately circular in outline.

Basioccipital. The basioccipital floors the posterior part of the cavum cranii and usually forms part of the condylus occipitalis. The morphology of the ventral surface of the basioccipital is somewhat variable among turtles. Most turtles possess variably developed paired tubercula basioccipitales, some may also develop a series of rugosities and depressions for muscular attachment (Gaffney 1979). In Eileanchelys waldmani, the basioccipital can only be observed in NMS G 2004.31.15 (Figs 3, 4). It contacts the basisphenoid anteriorly, the processus interfenestralis of the opisthotic anterodorsally and the exoccipital dorsally. The basioccipital-basisphenoid suture is either fused or not preserved in the specimen, but it can be approximately located (Fig. 3a, b). There is no contact between the basioccipital and pterygoid, which differs from what can be found in most pancryptodires (Joyce 2007). In contrast to Proganochelys quenstedti, Palaeochersis talampayensis and Australochelys africanus, the thickness of the basicranial floor (formed by the basioccipital and basisphenoid) is reduced in Eileanchelys waldmani. This reduction is characteristic of all more derived turtles, whereas the condition in Kayentachelys aprix is intermediate between the aforementioned species and other turtles (Sterli \& Joyce 2007). The ventral surface of the basioccipital is flat and proportionally wider than that of Kayentachelys aprix, Heckerochelys romani and Condorchelys antiqua. Posterolaterally, the basioccipital, along with the exoccipitals, develops a pair of dorsoventrally flattened tubercula basioccipitales. These structures are thicker and oriented more ventrally in Kayentachelys aprix, whereas their development in Heckerochelys romani and Condorchelys antiqua is difficult to estimate from published illustrations (Sukhanov 2006; Sterli 2008).

On the dorsal surface of the basioccipital (i.e., on the floor of the cavum cranii), the basis tuberculi basalis (Fig. 
$3 g, h)$ is preserved near the basisphenoid-basioccipital suture, but posteriorly there is no trace of the crista dorsalis basioccipitalis. It cannot be determined if the crista is genuinely absent or if this is merely a consequence of poor preservation, but in place of the crista there is a rounded concavity on this part of the braincase floor. As in other turtles, the basioccipital forms the posteroventral margin of the hiatus acusticus dorsoanterolaterally. Posteriorly the basioccipital forms at least part of the condylus occipitalis. It seems that the remainder of the condyle is formed by the exoccipitals, but their sutures with the basioccipital are closed (see Exoccipital, above). In contrast to the majority of turtles where it is a rounded triangular or oval structure, the condylus occipitalis of Eileanchelys waldmani is circular in posterior view (Fig. 3e, f). In E. waldmani, the basioccipital does not participate in the formation of either the fenestra perilymphatica (see Opisthotic, below) or the foramen jugulare anterius. This differs from Kayentachelys aprix where the basioccipital participates in both openings (Sterli \& Joyce 2007). In turtles, the fenestra perilymphatica is usually either formed by the opisthotic alone or by the opisthotic and a small ventromedial contribution from the basioccipital (Gaffney 1979). The foramen jugulare anterius is usually formed by the opisthotic anteriorly and exoccipital posteriorly, but the basioccipital often enters its ventral margin and forms a small part of the medial wall of the recessus scalae tympani (Gaffney 1979). Consequently, the formation of these two openings by the opisthotic and exoccipital to the exclusion of the basisphenoid in Eileanchelys waldmani is rather uncommon among turtles. However, the detailed anatomy of this region of the skull is rarely available in fossil turtles, so that comparisons are difficult.

Prootic. The prootic forms most of the anterior part of the otic chamber and is involved in the formation of numerous structures of the inner ear. In the turtle skull, the prootic has two main exposures: the first within the cavum acustico-jugulare where the prootic participates in the formation of the inner ear, and the second on the dorsal surface of the otic chamber where the prootic participates in the formation of diverse structures related to the temporosphenoidal area. In Eileanchelys waldmani, the prootic is exposed in ventral view (NMS G 2004.31.15; Figs $3 a, b$ and 4). This plesiomorphic condition is also present in Proganochelys quenstedti, Palaeochersis talampayensis, Odontochelys semitestacea, Kayentachelys aprix, Heckerochelys romani, Condorchelys antiqua and most panpleurodires, but not in Meiolania platyceps, Mongolochelys efremovi or Kallokibotion bajazidi in which the pterygoid extends posteriorly and covers the prootic as it does in pancryptodires (Joyce 2007).
In NMS G 2004.31.15, the prootic contacts the opisthotic posteriorly, the supraoccipital dorsomedially, the basisphenoid ventromedially, the pterygoid anteroventrally and the quadrate laterally. The prootic forms the anterior half of the large fenestra ovalis as well as the anterior wall of the cavum labyrinthicum (Fig. 4). Ventrally, the prootic contacts the anteroventral margin of the processus interfenestralis of the opisthotic. This contact is sutural for its anterior half, but it may have been cartilaginous posteriorly as a small space is present between these bones in NMS G 2004.31.15. Because of the sutural contact between the prootic and the processus interfenestralis of the opisthotic, the fenestra ovalis and cavum labyrinthicum are entirely floored. This feature is present in most stem turtles, but not in more derived turtles, or at least not in a homologous fashion: the cavum labyrinthicum of most pancryptodires is floored due to the posterior extent of the pterygoid. The recessus labyrinthicus prooticus of the cavum labyrinthicum is very large in Eileanchelys waldmani. Again, comparison is limited by the fact that this region is rarely available in fossils. In the anterior part of the cavum acustico-jugulare, the prootic forms the medial part of the canalis cavernosus. The canalis nervi facialis, which is formed by the prootic, opens in the dorsal roof of the canalis cavernosus just anterior to the posterior opening of the latter. The fact that the canalis nervi facialis opens within the canalis cavernosus, as in most turtles, is an indication of the posterior extent of the latter (see Pterygoid, above). Laterally, the prootic also forms the medial half of the aditus stapedio-temporalis, which is located approximately at the level of the anterior margin of the fenestra ovalis as in Kayentachelys aprix (Sterli \& Joyce 2007, p. 686). As in most turtles, the prootic forms the anterior margin of the hiatus acusticus, the fossa acustico-facialis and the anterolateral wall of the braincase (all of this is visible within the cavum cranii of NMS G 2004.31.15).

On the dorsal surface of the otic chamber most of the sutures are either fused or not preserved, so that the relationships between the prootic, supraoccipital, parietal, quadrate and opisthotic remain conjectural. This part of the prootic is severely damaged in NMS G 2004.31.15 and corresponds to where the specimen was eroded prior to collection (Fig. 3g, h). The prootic apparently forms the medial half of the foramen stapedio-temporale, the lateral half being formed by the quadrate. A trough curving anteromedially from the foramen stapedio-temporale marks the passage of the stapedial artery on the dorsal surface of the supposed prootic (Fig. 3c, d). Although this area is damaged, there is no evidence of a processus trochlearis oticum on the quadrate and prootic. The anteromedial part of the 
prootic is missing in NMS G 2004.31.15, so that the presence of a prootic foramen (resulting from an ossification of the pila prootica between the processus clinoideus and the prootic, which is found in Proganochelys quenstedti and Kayentachelys aprix) and the development of the foramen nervi trigemini cannot be assessed.

Opisthotic. The opisthotic forms the posterior part of the otic chamber and the posterolateral wall of the braincase. It roofs the posterior part of the cavum acustico-jugulare and possesses a lateral process, the processus paroccipitalis, that has a broad sutural contact with the squamosal and quadrate (the location of a former kinetic joint in the ancestral tetrapod skull; see Romer 1956; Gaffney 1990). Finally, the opisthotic is characterised by a ventromedial process, the processus interfenestralis, which plays an important role in various structures of the inner ear. NMS G 2004.31.15 is the only specimen in which the opisthotic can be observed (Figs 3, 4). It contacts the supraoccipital dorsomedially, the prootic anteriorly, the basioccipital ventrally, the quadrate laterally, the squamosal posterolaterally and the exoccipital posteromedially. On the dorsal surface of the otic chamber, the sutures of the opisthotic with the prootic and supraoccipital are either fused or not preserved, so that it is unclear whether or not the opisthotic is involved in the formation of the foramen stapedio-temporale. The processus paroccipitalis is flattened dorsoventrally and extends posteriorly beyond the level of the condylus occipitalis (left side of NMS G 2004.31.15). The lateral extent of the processus paroccipitalis is somewhat variable among turtles, being for example short in Chelonia mydas (the green turtle) and long in podocnemids (Gaffney 1979, p. 136). In Eileanchelys waldmani, the processus paroccipitalis of the opisthotic reaches the level of the condylus mandibularis laterally, which is similar to the extent present in most turtles.

As described above (see Prootic), the processus interfenestralis of the opisthotic has a sutural contact with the prootic and this contact floors the fenestra ovalis and cavum labyrinthicum. The processus interfenestralis also has a broad sutural contact with the basioccipital ventrally, so that there is no hiatus postlagenum. The development of the processus interfenestralis of the opisthotic in Eileanchelys waldmani is intermediate between the robust, thick structure seen in the most basal turtles (i.e., Proganochelys quenstedti, Palaeochersis talampayensis, Australochelys africanus and Kayentachelys aprix) and the slender, flattened sheet of bone seen in most crown-group turtles. The processus interfenestralis of Eileanchelys waldmani is still a relatively large element with respect to the rest of the skull, but it is considerably flattened and reaches the basicranium floor ventrally, which is not the case in more basal taxa. However, it is not the transverse sheet of bone that forms a proper anterior wall to the recessus scalae tympani as seen in more derived turtles. It is difficult to assess the morphology of the processus interfenestralis in Heckerochelys romani and Condorchelys antiqua based on the published illustrations (Sukhanov 2006; Sterli 2008), but it appears to be more robust in these taxa than in Eileanchelys waldmani. As in all turtles, the base of the processus interfenestralis is pierced by the foramen externum nervi glossopharyngei. The processus interfenestralis of the opisthotic forms the posterior and posteroventral margins of the fenestra ovalis, as well as the posterior half of the cavum labyrinthicum (Fig. 4). The processus interfenestralis forms most of the fenestra perilymphatica, but a ventromedial contribution from the exoccipital is uncommon among turtles. Usually, when the fenestra perilymphatica is not entirely contained within the opisthotic, it is the basioccipital that forms the ventromedial part of it. The processus interfenestralis of the opisthotic also forms the posterior margin of the hiatus acusticus, the anterodorsal margin of the foramen jugulare anterius and the anterolateral margin of the foramen jugulare intermedium.

The fenestra ovalis of Eileanchelys waldmani is a relatively large triangular opening that faces laterally. The fenestra ovalis of more derived turtles appears to be proportionally smaller, but there is currently no detailed survey of this character among turtles. Finally, several foramina and canals associated with the membranous inner ear (semicircular canals) are preserved in the roof of the cavum labyrinthicum (formed by the prootic and opisthotic). However, these are not readily observable and their description would require further investigation (e.g., following CT-scanning).

Basisphenoid. The basisphenoid forms the anteroventral floor of the cavum cranii. In turtles, the basisphenoid is actually composed of the fused basisphenoid and parasphenoid of other reptiles (Romer 1956; Gaffney 1979). The morphology of the basisphenoid is relatively important for turtle systematics (e.g., Gaffney 1979; Gaffney \& Meylan 1988; Joyce 2007). Unfortunately, most of the basisphenoid is unknown in Eileanchelys waldmani. The posteriormost part of the basisphenoid is preserved in NMS G 2004.31.15 (Fig. 3a, b) and some internal parts of the basisphenoid seems to be observable in NMS G 2004.31.16e, but the latter are extremely difficult to interpret. In NMS G 2004.31.15, the basisphenoid is broken posterior to the level of the basipterygoid process (if present; see Pterygoid, above) and only the posterior part of the bone is preserved. The basisphenoid contacts the pterygoid laterally, the prootic 
posterolaterally and the basioccipital posteriorly. Most of the sutures of the basisphenoid with neighbouring bones are all either closed or not visible in the specimen. Posteriorly, at the level of the supposed basisphenoidbasioccipital suture, the basisphenoid has two small ventral protuberances that appear symmetrical and could have served as muscular attachment sites, but these might also be artefacts because the preservation of the bone surface in this area is not very good. In contrast to Kayentachelys aprix and Condorchelys antiqua (Sterli \& Joyce 2007; Sterli 2008), there is no evidence of paired pits on the ventral surface of the basisphenoid. However, this area is severely damaged in NMS G 2004.31.15 and a definitive conclusion is impossible to reach.

Dorsally (i.e., on the floor of the cavum cranii), the basisphenoid forms the anteroventral margin of the hiatus acusticus but it does not seems to participate in the floor of the cavum labyrinthicum, in contrast to Kayentachelys aprix (Sterli \& Joyce 2007). Anteriorly, the basisphenoid is broken just posterior to the dorsum sellae so not much can be said about the dorsal morphology of this bone (e.g., sella turcica, processus clinoideus, foramen anterius canalis carotici interni, rostrum basisphenoidale).

The carotid arterial system has been a major source of information for systematists (e.g., Gaffney 1979; Gaffney \& Meylan 1988; Meylan \& Gaffney 1989; Gaffney et al. 1991; Gaffney 1996; Shaffer et al. 1997; Brinkman \& Wu 1999; Hirayama et al. 2000; Jamniczky et al. 2006; Jamniczky \& Russell 2007; Joyce 2007; Jamniczky 2008). This is mainly because the location of the foramen posterius canalis carotici interni (fpcci), the foramen through which the carotid artery enters the bony skull, is notably variable within the major turtle clades. The fpcci opens medially in the ventral surface of the basisphenoid in most stem turtles, which represents the plesiomorphic reptilian condition (Romer 1956). In panpleurodires, the fpcci is formed by the prootic and/or the basisphenoid (laterally) with sometimes a small contribution by the quadrate. Two morphologies occur in pancryptodires: in paracryptodires, the fpcci is formed by the pterygoid and basisphenoid halfway along the suture between two bones, whereas in eucryptodires, the fpcci is formed mostly or fully by the pterygoid and located near the posterior end of the basisphenoid or even further posteriorly. In Proganochelys quenstedti, Kayentachelys aprix, Heckerochelys romani, Condorchelys antiqua, Mongolochelys efremovi and Kallokibotion bajazidi (i.e., in all stem turtles, with the exception of Meiolania platyceps), the fpcci opens fully within the basisphenoid. The fpcci is not preserved in any specimen of Eileanchelys waldmani, but the morphology of NMS G 2004.31.15 suggests that the fpcci opens within the basisphenoid as in most other stem turtles.

\subsection{Mandibular elements}

Mandibular elements are associated with two of the paratype skulls (NMS G 2004.31.16d and NMS G 2004.31.16f), but their state of preservation prevents any useful comparisons. In NMS G 2004.31.16d (Fig. 5), the mandible is closely appressed to the skull so that only some parts of the lateral and ventral portion of the lower jaw can be observed. The dentary is the only mandibular bone identifiable in the latter specimen. It is apparently fused to the other dentary anteromedially at the symphysis. Its lateral surface is perforated by multiple small foramina, presumably serving as nutrient canals for the rhamphotheca (Gaffney 1979). Medial to the left dentary in NMS G 2004.31.16d (ventral view), there are several splinters of bone that might represent the angular and/or the splenial, but their identity cannot be determined. In NMS G 2004.31.16f (Fig. 7), only the lateral surface of the left mandibular ramus is visible. In this specimen the mandible is also appressed to the skull. The left ramus can be followed from a point close to the symphysis to the area articularis mandibularis posteriorly. The dentary appears to be a very elongate bone in lateral view. Posteriorly, the left ramus is damaged at the level of the processus coronoideus and of the dentary-surangular suture, so that this suture is impossible to follow. Most of the surangular is preserved and the foramen nervi auriculotemporalis is clearly apparent on its lateral surface. Two smaller foramina are present close to the foramen nervi auriculotemporalis: one slightly anterior and one slightly posteroventral. These smaller foramina may be subdivisions of the foramen nervi auriculotemporalis (Gaffney 1979). Posteriorly, the surangular has a broad subvertical contact (in lateral view) with the articular. Halfway along the lateral suture between the surangular and the articular there is a relatively large foramen or circular depression that cannot be identified, but that is probably an artefact of preparation. Posteriorly, the articular is damaged and the area articularis mandibularis is only partly preserved. The posterior process of the dentary does not appear to reach the articular. Because the mandible is appressed to the skull in both NMS G 2004.31.16d and NMS G 2004.31.16f, no information on the mandibular triturating surface is available. In Eileanchelys waldmani the mandible is an elongate and relatively thin structure that differs significantly from the high, robust mandible of Kayentachelys aprix (Sterli \& Joyce 2007). 


\section{Shell morphology (Figs 9-14)}

The carapace can be best seen in NMS G 2004.31.16b and NMS G 2004.31.16c, and the anteromedial rim of the carapace is preserved in NMS G 2004.31.16d. The anterior half of the plastron can be best seen in NMS G 2004.31.16d and NMS G 1992.47.50. The posterior half of the plastron is partly observable in NMS G 2004.31.16b, although it has suffered significant postmortem deformation. The plastron is also preserved in NMS G 2004.31.16a, but it is missing the anterior and posterior parts and most scale sulci.

\subsection{Carapace}

Nuchal. The nuchal, the single anteromedian plate of the carapace, is at least partly preserved on NMS G 2004.31.16a (Fig. 9), NMS G 2004.31.16b (Fig. 10), NMS G 2004.31.16d (Fig. 12) and NMS G 2004.31.16c (Fig. 11), but it is best seen on the latter specimen. The nuchal consists of a large trapezoidal element that is wider than long. It contacts the first neural posteromedially, the first costal posterolaterally (on both sides) and at least the first peripheral laterally. The number of peripherals contacted by the nuchal is unclear as no specimen has a complete nuchal. However, as in most turtles, it is probable that the nuchal only contacted peripheral 1 laterally (NMS G 2004.31.16b and NMS G 2004.31.16c; see Figs 10, 11). The contact with peripheral 1 is straight and faces anterolaterally. The posterolateral contact with costal 1 is also straight and may have faced slightly anteromedially. This morphology is very common among turtles from both the stem- and the crown-group. The nuchal emargination (the anteromedian emargination of the carapace formed by the nuchal plate) is very shallow (NMS G 2004.31.16c and NMS G 2004.31.16d). This is also very common in turtles and among stem turtles it is known at least in Kayentachelys aprix and Heckerochelys romani.

Neurals. The neural plates form a median row of unpaired elements in the carapace. Their number can be somewhat variable, but it is usually eight (Zangerl 1969). Ventrally, the neural plates are fused with the neural arch of the dorsal vertebrae. The neurals can be observed in NMS G 2004.31.16b (Fig. 10), NMS G 2004.31.16c (Fig. 11) and NMS G 2004.31.16d (Fig. 12). In NMS G 2004.31.16c, eight well-developed, elongate neurals are present. In NMS G 2004.31.16b, the anterior neurals are missing, but geometrical relationships allow identification of the seventh and eighth neurals. Posterior to the eighth neural of NMS G 2004.31.16b is an additional plate. This additional element does not appear to result from the subdivision of an adjoining plate. Its shape (elongate and trapezoidal; see below) differs from that of the first eight neurals and from that of the two posterior suprapygals. As no visceral view of the carapace is available, it is impossible to state whether this plate is a ninth neural (which would be fused to the neural arch of an underlying vertebra) or a supernumerary suprapygal (which would not have a ventral relation to the axial skeleton). The presence of nine neurals has been suggested or discussed for several stem turtles. Gaffney et al. (1987) recorded nine neurals in their original description of Kayentachelys aprix, but according to Joyce \& Sterli (pers. comm. 2007) this is impossible to confirm based on the available material. The number of neurals is uncertain in Heckerochelys romani, but it may have been nine (Sukhanov 2006). According to Sukhanov (2000), Mongolochelys efremovi has nine neurals. Nine neurals are also described in Indochelys spatulata Datta et al., 2000. In all of these species, as in Eileanchelys waldmani, the presence of nine neurals remains conjectural as no visceral view of the carapace confirms the relationship between this supposed ninth neural and the axial skeleton.

All neurals in Eileanchelys waldmani consist of rectangular elements that are approximately twice as long as they are wide. Neural 1 is the only neural for which the exact outline is known (NMS G 2004.31.16c; Fig. 11); all other neurals are partly damaged. Neural 1 has a slightly convex anterior margin for the contact with the nuchal, concave lateral margins contacting the first costals, a concave posterior margin, which contacts neural 2, and straight and short posterolateral margins contacting the second costals. This gives neural 1 a stretched hexagonal outline with short posterior sides. In turtles, neurals often have the shape of stretched hexagon with short anterior sides. Neural 1 also appears to be the largest neural. The first neural of Eileanchelys waldmani greatly resembles that of Kayentachelys aprix, and to a lesser extent that of Heckerochelys romani, although in the latter neural 1 is much more elongate than in the aforementioned species. In addition to the first and third neurals, neural 2 contacts costal 2 for most of its length as well as the anteromedial part of costal 3 posterolaterally. The contacts of costals 3 and 4 are unclear and costal 4 is poorly preserved in all specimens. The contacts of neural 5 with neighbouring costals are not preserved in any specimen, but from the contacts of neural 6 it can be concluded that neural 5 contacts costal 4 and probably also costal 5. Neurals 6, 7 and 8 are proportionally shorter than the anterior neurals, but they are still longer than wide. Neural 6 contacts mostly costal 5 and a posterolateral contact with costal 6 is absent or very reduced. Similarly, neural 7 mostly contacts costal 6 and might have a short contact with costal 7 posterolaterally. Neural 8 only contacts costal 7 laterally 
a

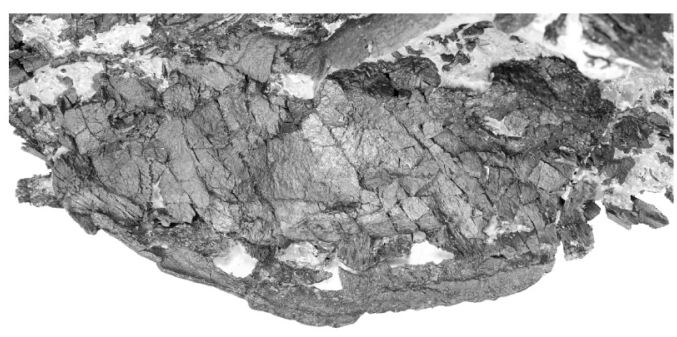

b

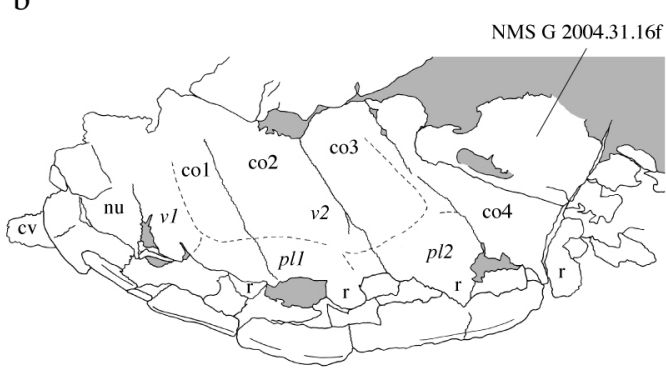

e

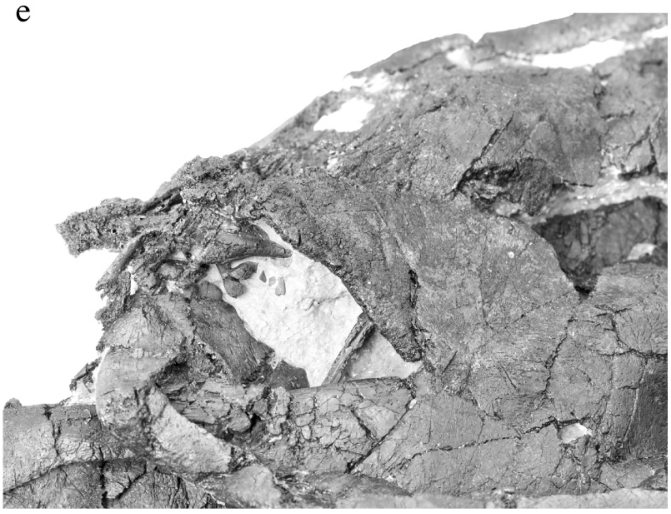

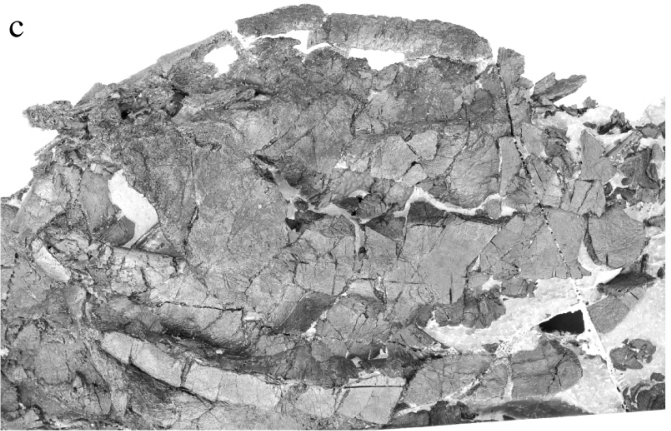

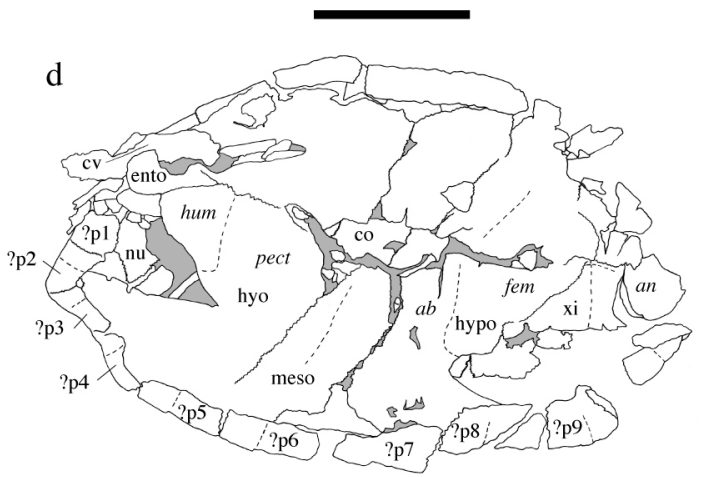

f

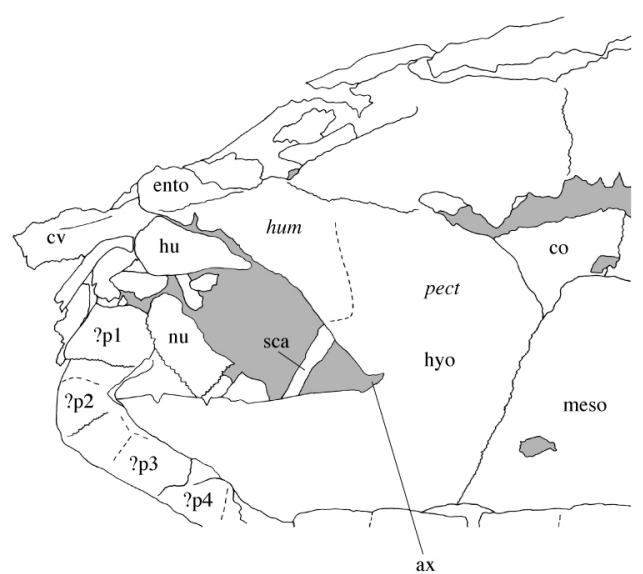

Figure 9 - Eileanchelys waldmani, NMS G 2004.31.16a. (a, b) carapace (anterior to the left); (c, d) plastron; (e, f) enlargement of the anterior plastral area. Epidermal scale are in italics. Scale bars: (a-d) 50 mm; (e, f) 10 mm. Abbreviations: ab, abdominal scale; an, anal scale; ax, axillary notch; co, costal plate; cv, cervical vertebra; ento, entoplastron; fem, femoral scale; hu, humerus; hum, humeral scale; hyo, hyoplastron; hypo, hypoplastron; meso, mesoplastron; nu, nuchal; p, peripheral plate; pect, pectoral scale; pl, pleural scale; $r$, dorsal rib; sca, scapula; v, vertebral scale; xi, xiphiplastron.

posterolaterally. Neural 8 only contacts costal 7 laterally and may be the smallest plate of the series.

The additional median plate (possible ninth neural or supernumerary suprapygal) has a remarkable shape: it is an elongate trapezoid with the anterior margin significantly shorter than the posterior margin and with somewhat concave lateral margins. It contacts the eighth neural anteriorly, the first suprapygal posteriorly and the eighth costal laterally. This shape differs markedly from that of the neurals and suprapygals of the same species and this additional plate does not appear to result from the splitting of either an adjoining neural or suprapygal as may occur in some turtles with additional plates. Moreover, this plate resembles the possible ninth neural of Heckerochelys romani as reconstructed by Sukhanov (2006, fig. 3).

Suprapygals. The suprapygals are unpaired elements that are located posterior to the neural row. There are usually two suprapygals. Their development and shape are extremely variable among turtles (the first usually being the smaller of the two), which makes them valuable for systematic purposes. Suprapygals, in contrast to 
neurals, do not have sutural relationships with the underlying axial skeleton. In Eileanchelys waldmani, there are at least two suprapygals easily identifiable by their shape: they are very wide crescent-shaped elements with the concavity facing anteriorly (NMS G 2004.31.16b; Fig. 10). Due to deformation, suprapygal 1 may have had a lens-shape with slightly convex anterior and posterior margins. Suprapygal 1 is very narrow anteroposteriorly and it is remarkable that it reaches the peripheral row laterally. In most turtles, suprapygal 2 has an anterolateral contact with the last costal that prevent suprapygal 1 from contacting the peripherals. In Eileanchelys waldmani, the first suprapygal contacts what is putatively (see Peripherals, below) the tenth peripheral laterally, preventing a contact between costal 8 and suprapygal 2. To date, among stem turtles, only Kallokibotion bajazidi is known to have a contact between the first suprapygal and a peripheral (the eleventh), but aside from this the morphology of the pygal region in $\mathrm{K}$. bajazidi is radically different from that of Eileanchelys waldmani (see Gaffney \& Meylan 1992, fig. 17). In E. waldmani, suprapygal 1 contacts the additional plate (see above) anteromedially, the eighth costal anterolaterally, the putative peripheral 10 laterally and the second suprapygal posteriorly. On the dorsal surface of both suprapygals, there is a low medial keel that continues posteriorly on the pygal. Suprapygal 2 is a broad crescentshaped plate that is longer than suprapygal 1, but that is still broader than long (actually, almost three time wider than long). Its anterior margin, which only contacts suprapygal 1, is slightly concave. Laterally, suprapygal 2 contacts the putative peripherals 10 and 11. Posteriorly, it has a broad convex contact with the pygal. A comparable morphology of the second suprapygal may be found in Indochelys spatulata in which suprapygal 2 is a boomerang-shaped element that contacts the tenth and eleventh peripherals laterally. However, the morphology of suprapygal 1 in Indochelys spatulata is different from that of Eileanchelys waldmani. In Heckerochelys romani and Mongolochelys efremovi, the second suprapygal is also a broad element, but it is rather trapezoidal in shape, whereas the first suprapygal is significantly reduced compared to that of Eileanchelys waldmani. In Condorchelys antiqua, both suprapygals are markedly reduced compare to that of the Skye species.

Pygal. The pygal is a single element that forms the posteromedial portion of the rim of the carapace. Its shape and development is variable among turtles, depending for example on the posterior outline of the carapace (i.e., the presence or absence of a caudal emargination). In Eileanchelys waldmani, the pygal is a simple rectangle about the size of the neighbouring peripherals (NMS G 2004.31.16b; Fig. 10). It is slightly arched along the posterior margin of the second suprapygal and contacts the putative eleventh peripherals on both sides. The slight medial keel that is observed on the suprapygal is also present on the pygal. There is no evidence of a caudal emargination along the posterior rim of the carapace. The morphology of the pygal in Eileanchelys waldmani corresponds to that found in most turtles. For example, within stem turtles, this morphology is also found in Heckerochelys romani, Condorchelys antiqua and Mongolochelys efremovi.

Costals. The costals are paired, band-like elements that form most of the lateral part of the carapace. Each costal plate is fused to an underlying rib, which may stick out at the lateral end of the costal and insert into the peripherals in some turtles (Zangerl 1969). On its visceral side, each costal has a rib head that protrudes ventromedially and that articulates with the dorsal vertebrae. Most turtles have eight pairs of costals, but nine pairs have been recorded in Proganochelys quenstedti, Condorchelys antiqua and Mongolochelys efremovi (Gaffney 1990; Khosatzky 1997; Sukhanov 2000; Sterli 2008). Gaffney et al. (1987) also described nine costals in Kayentachelys aprix, but a recent review of the original material as well as newly discovered specimens was unable to reproduce this observation (Joyce \& Sterli pers. comm. 2007). Costals can be observed in all four carapaces from the paratype association, but they are best seen in NMS G 2004.31.16b (Fig. 10) and NMS G 2004.31.16c (Fig. 11). The posterior part of the carapace is damaged in NMS G 2004.31.16c, but it is possible to see the first seven costal plates. In NMS G 2004.31.16b, the anterior part of the carapace is severely damaged, but the comparison with NMS G 2004.31.16c enables the identification of most carapacial plates and it appears that Eileanchelys waldmani has eight costals. As described for Kayentachelys aprix (Joyce \& Sterli pers. comm. 2007), there is a slight curving of the first two costals toward the anterior end of the carapace in Eileanchelys waldmani. This anterior curving is also present in Indochelys spatulata and Mongolochelys efremovi. In contrast, costal 3 appears to be perpendicular to the neural row and, as in most turtles, the posterior costals (4-8) seem to bend increasingly toward the posterior end of the carapace, although this is not obvious due to the preservation of the specimens.

If a count of eleven pairs of peripherals is considered (see Peripherals, below), then the contacts are as follows: costal 1 contacts peripherals 2 and 3 and maybe also peripheral 1; costal 2 contacts peripherals 3 and 4; costal 3 contacts peripherals 4 and 5; costal 4 contacts peripherals 5 and 6; costal 5 contacts peripherals 6 and 7; costal 6 contacts peripherals 7 and 8; costal 7 contacts peripherals 8 and 9; and costal 8 contacts peripherals 9 
a
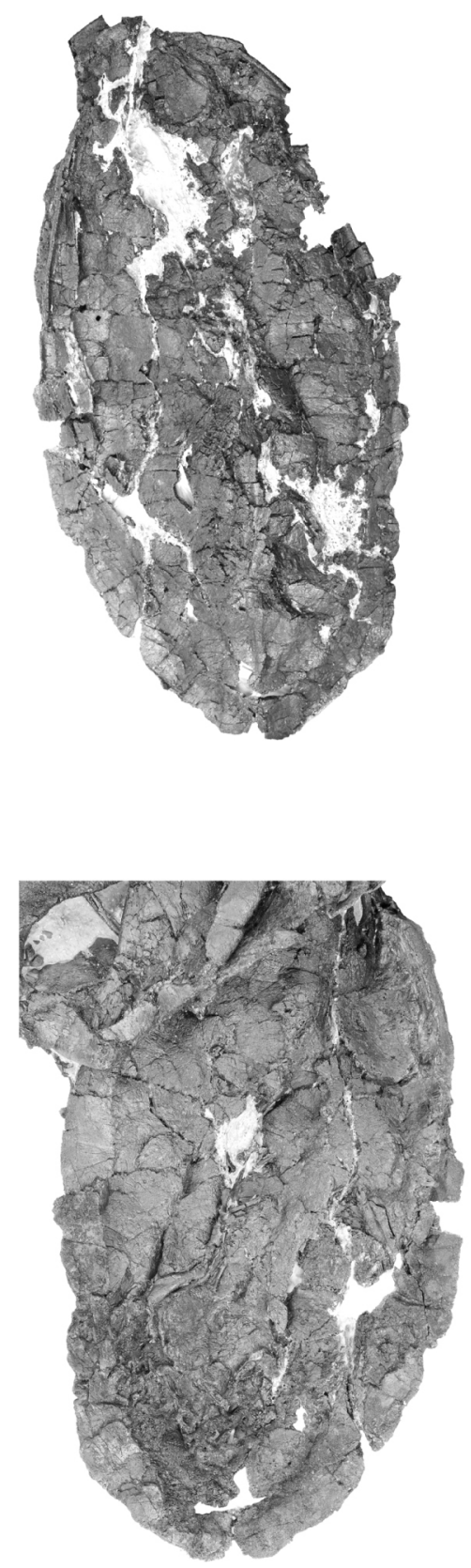

b
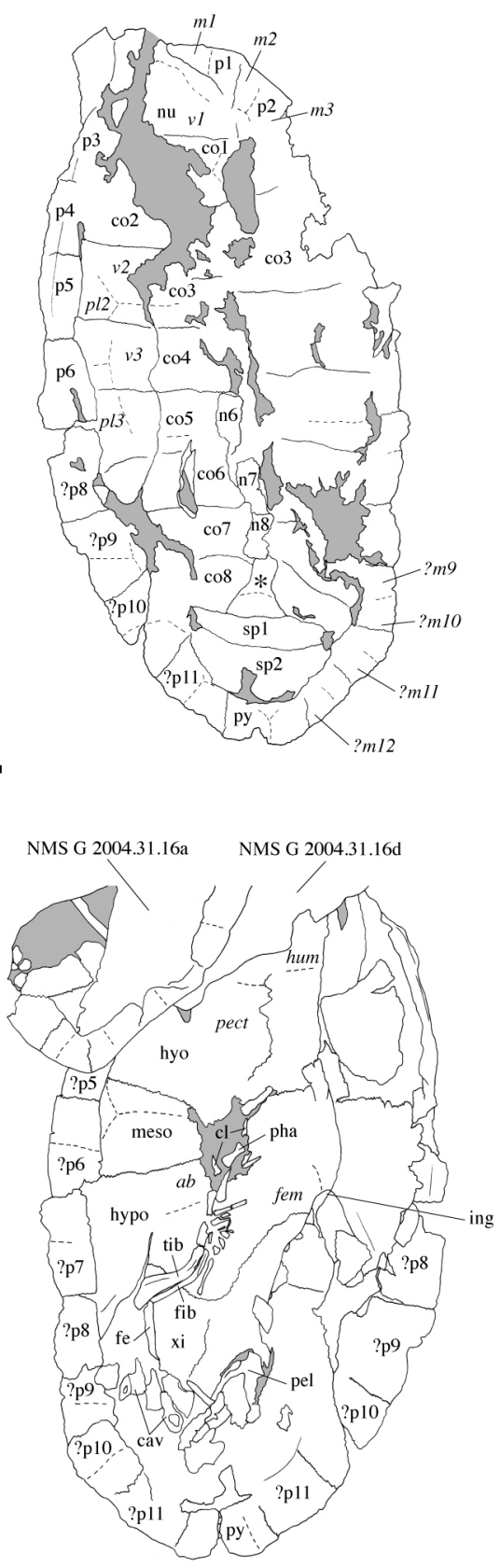

Figure 10 - Eileanchelys waldmani, NMS G 2004.31.16b. (a, b) carapace; (c, d) plastron. Epidermal scales are in italics. Scale bars: $50 \mathrm{~mm}$. Abbreviations: ab, abdominal scale; cav, caudal vertebra; cl, claw; co, costal plate; fe, femur; fem, femoral scale; fib, fibula; hum, humeral scale; hyo, hyoplastron; hypo, hypoplastron; ing, inguinal notch; m, marginal scale; meso, mesoplastron; $n$, neural plate; nu, nuchal plate; p, peripheral plate; pect, pectoral scale; pel, pelvis; pha, phalange; pl, pleural scale; py, pygal plate; sp, suprapygal plate; tib, tibia; v, vertebral scale; xi, xiphiplastron; *, supernumerary plate.

and 10. This is the general pattern found in most turtles. Small costal fontanelles (i.e., incomplete ossification of the distal end of the costal plates that fail, completely or partly, to contact the peripherals, except for the distal end of the ribs) are present in NMS G 2004.31.16a (Fig. 9a, b), but are absent in all other individuals. This suggests that NMS G 2004.31.16a is a slightly younger individual, because its morphology is otherwise congruent with that of associated specimens. Due to intensive deformation, the exact size of these specimens is difficult to assess, so that this hypothesis could not be confirmed by specimen measurements (see section 7.1).

Peripherals. The peripherals are the bony plates that form the rim of the carapace, with the exception of the anteromedial- and posteromedialmost portions, which are formed by the nuchal and pygal respectively. Peripherals are usually flat, wedge-shaped elements, except in the bridge region where they are sutured to the 
plastron, which gives them a 'V'-shaped cross-section. No complete row of peripherals is known in any specimen of Eileanchelys waldmani, so that the number of peripherals is unclear. According to the different counts on each specimen (mostly on NMS G 2004.31.16b and NMS G 2004.31.16a; see Figs 9, 10) and the correlation between them, it appears that $E$. waldmani would have eleven pairs of peripherals, as it is usual for most turtles (Zangerl 1969). Proganochelys quenstedti and Proterochersis robusta Fraas, 1913 have more than eleven pairs of peripherals, but Kayentachelys aprix, Heckerochelys romani, Mongolochelys efremovi, Meiolania platyceps, panpleurodires and most pancryptodires have eleven pairs of peripherals (Joyce 2007, p. 31). Following the two previous statements, it is reasonable to consider that Eileanchelys waldmani has eleven pairs of peripherals.

Peripheral 1 differs from the others in its triangular shape: it tapers medially along the lateral margin of the nuchal plate. All other peripherals have a quadrangular shape and are more elongate than they are wide. The contacts between peripherals and costals are described above (see Costals). Peripherals 8 to 11 are larger than the anterior ones, mostly because they taper laterally for a greater extent. A sharp tapering of the posterolateral margin of the carapace is common among turtles. In contrast to most turtles, in which only peripheral 11 contacts the suprapygals (usually only the second) and pygal, peripheral 10 also contacts the suprapygals in Eileanchelys waldmani. Peripheral 11 contacts the pygal posteromedially and the second suprapygal anteromedially. Medially and from posterior to anterior, peripheral 10 contacts suprapygal 2, suprapygal 1 and costal 8. Among stem turtles, Indochelys spatulata and perhaps also Mongolochelys efremovi are the only species in which peripheral 10 contacts suprapygal 2, although in these species suprapygal 1 does not contact the peripherals laterally (see Suprapygals, above). Specimens NMS G 2004.31.16a and NMS G 2004.31.16b show that the bridge in Eileanchelys waldmani is extensive and that peripherals 2 to 8 are the bridge peripherals. This corresponds to the morphology in Kayentachelys aprix (Joyce \& Sterli pers. comm. 2007). In most other turtles, the bridge extends from peripherals 3 or 4 to peripherals 7 or 8 . This is only a tentative observation as no comprehensive review of this feature is available in the literature. In contrast to Heckerochelys romani in particular, the bridge of Eileanchelys waldmani is osseous.

Fossil turtle shells are often flattened during fossilisation, so that the original doming of the shell remains unsuspected. For example, all known shells of Kayentachelys aprix are flat, leading Gaffney et al. (1987, p. $290)$ to describe the shell of this species as being "moderately low-domed". However, a recent review of the material proved this assertion to be incorrect (Joyce \& Sterli pers. comm. 2007). Similarly, all available shells of Eileanchelys waldmani are more or less flattened, but bridge peripherals of several specimens have a morphology similar to that described for Kayentachelys aprix by Joyce \& Sterli (pers. comm. 2007). Specimens NMS G 2004.31.16b and NMS G 2004.31.16c show that peripherals 3 to 7 have a deep longitudinal gutter dorsally as well as a steeply ascending medial margin where they meet the costals (Figs 10, 11). NMS G 2004.31.18, an isolated row of bridge peripherals preserved in three dimensions, shows an angle of approximately 90 degrees between the ventral and dorsal branches of the V-shaped peripherals. These specimens demonstrate that Eileanchelys waldmani had a fairly domed shell. Based on the highly domed shell of most extant terrestrial forms (e.g., Chelonoidis nigra, the Galápagos giant tortoise) and the flattened shell of many extant aquatic species (e.g., Chelodina expansa, Chelonia mydas, Trachemys scripta), it would be tempting to assume a direct link between possession of a domed shell and terrestriality and, conversely, between a flattened shell and aquatic habits. However, this link does not exist among extant turtles, as demonstrated by the highly domed shell of some aquatic forms: e.g., Cuora amboinensis, Pelusios carinatus and several Kinosternon species, including $K$. subrubrum. Similarly, several extant terrestrial taxa possess a flattened shell: e.g., Malacochersus tornieri (the pancake tortoise), Geoemyda spengleri, and all five Homopus species (Bonin et al. 2006). Moreover, jumping to conclusions about the habitat preference of stem turtles, which have no close relationships with extant clades, based only on the shell shape of extant species would be hazardous. In other words, the domed shells of Kayentachelys aprix and Eileanchelys waldmani should probably not be used as an indication of their habitat preferences.

Cervical scale. The cervical scale can be seen as the epidermal equivalent of the dermal nuchal plate, although the cervical scale is always greatly reduced compared to the size of the nuchal. In Eileanchelys waldmani, the cervical scale was a broad but short rectangular element lying entirely on the nuchal plate and that contacted the first marginal scale laterally and the first vertebral scale posteriorly (NMS G 2004.31.16b, NMS G 2004.31.16c and NMS G 2004.31.16d; Figs 10-12). The cervical scale appears to have been less wide in NMS G 2004.31.16d than in the other two aforementioned specimens, but this may be an intraspecific variation. This morphology is relatively common among chelonians and, concerning stem turtles only, it is found in Proganochelys quenstedti, Proterochersis robusta, Kayentachelys aprix, Heckerochelys romani and Meiolania platyceps. 
a

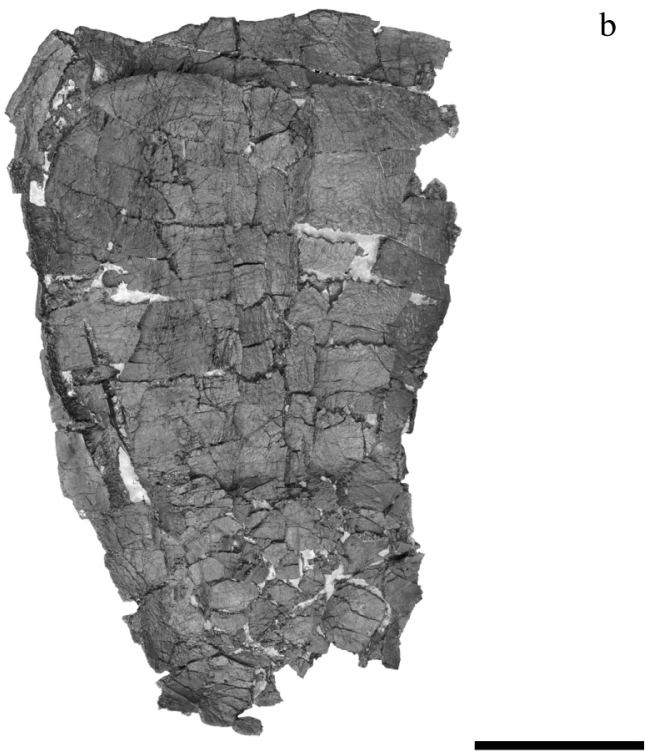

b

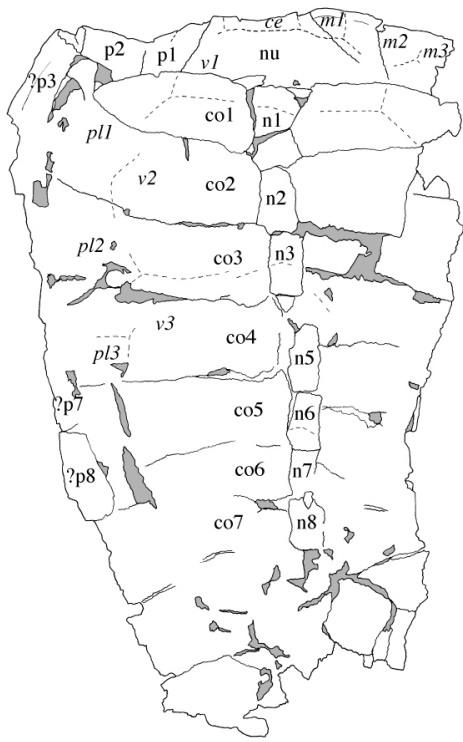

Figure 11 - Eileanchelys waldmani, NMS G 2004.31.16c. (a, b) carapace. Epidermal scales are in italics. Scale bar: 50 mm. Abbreviations: ce, cervical scale; co, costal plate; m, marginal scale; $n$, neural plate; nu, nuchal plate; p, peripheral plate; pl, pleural scale; v, vertebral scale.

Vertebral scales. The vertebral scales are unpaired elements that form the median row of the epidermal layer of the carapace. Proganochelys quenstedti is unique among turtles in having only four vertebral scales. All other turtles with epidermal scales have at least five vertebrals (some have six). The combination of observations from NMS G 2004.31.16a (Fig. 9), NMS G 2004.31.16b (Fig. 10), NMS G 2004.31.16c (Fig. 11) and NMS G 2004.31.16d (Fig. 12) indicates that Eileanchelys waldmani had five vertebral scales, but little information can be gathered on their outlines. The vertebral scales were notably wide (about 2.5 times wider than long), a plesiomorphic characteristic that is usual in the basalmost turtles (i.e., Proganochelys quenstedti, Proterochersis robusta, Kayentachelys aprix, Indochelys spatulata, Heckerochelys romani and Condorchelys antiqua). Vertebrals 2 and 3 appear to have been the widest vertebral scales. Vertebral 1 contacted the cervical scale anteromedially, marginals 1 and 2 anterolaterally, the first pleural posterolaterally and the second vertebral posteriorly. The vertebral 1-2 sulcus is mostly straight and transverse, except for a slight protrusion on the midline. This sulcus passes through the anterior half of neural 1. On each side, vertebral 2 had two oblique lateral margins, the anterior of which may have been slightly longer than the posterior. The vertebral 2-3 sulcus is located on the posterior part of the third costal and passes through the middle of neural 3. Vertebral 3 had two lateral margins that were oblique, but less so than those of vertebral 2 , and equal in length. The vertebral 3-4 sulcus is located on the posterior part of costal 5 and passes through the posterior half of neural 6 . The vertebral 4-5 sulcus is only partially apparent on NMS G 2004.31.16b (Fig. 10a, b) and it passes through the posterior half of the additional medial plate (ninth neural or supernumerary suprapygal).

Pleural scales. The pleural scales cover the lateral side of the carapace between the vertebrals and the marginals. Most turtles have four pairs of pleural scales. In relation to the broadened vertebral scales (see above), the pleurals of many basal turtles, including Eileanchelys waldmani, are reduced in width compared to those of more derived turtles. In E. waldmani, the pleurals were notably more elongate than they were wide. This arrangement of the pleural and vertebral scales is similar to that found in Proganochelys quenstedti, Proterochersis robusta, Kayentachelys aprix, Heckerochelys romani and Condorchelys antiqua. Pleurals 1 and 2 are partly visible on NMS G 2004.31.16c (Fig. 11), whereas only pleurals 2 and 3 are observable on NMS G 2004.31.16b (Fig. 10). The pleural 1-2 sulcus is probably mostly on costal 2 and the pleural 2-3 sulcus is on costal 4.

Marginal scales. The marginal scales are the epidermal equivalent of the dermal peripheral plates. Most turtles usually have twelve pairs of marginals, although some of the basalmost forms (i.e., Proganochelys quenstedti and Proterochersis robusta) have more than twelve pairs. As for the peripherals (see above), no complete row of marginals is known for Eileanchelys waldmani. The marginal sulci are poorly preserved in the available specimens, but because a close correlation exists among turtles between the number of peripherals and that of marginals (Joyce 2007, p. 31) it is probable 
that $E$. waldmani had twelve pairs of marginals. Marginals 1 and 2 are apparent in NMS G 2004.31.16c (Fig. 11). The first marginal was smaller than the second and overlapped both the nuchal and the first peripheral. Marginal 2 lay on peripherals 1 and 2, and did not overlap the nuchal or the first costal. Posterior marginals (probably marginals 8 to 12 ) are visible on NMS G 2004.31.16b (Fig. 10). It is unknown whether or not some of these overlapped the costals medially. The last pair of marginals (probably the twelfth) met each other along the midline, as it is usual in turtles. In contrast to Proganochelys quenstedti, Palaeochersis talampayensis and Proterochersis robusta, there is no evidence of supramarginal scales in Eileanchelys waldmani.

A tentative reconstruction of the carapace of Eileanchelys waldmani is provided in Figure 14.

\subsection{Plastron}

Epiplastron. The epiplastron is a paired element that forms most, if not all, of the anterior rim of the plastron. It is generally understood that the epiplastra are homologous to the clavicles of other reptiles (e.g., Zangerl 1939; Walker 1947). In Eileanchelys waldmani, the epiplastron is a relatively small element that contacts the hyoplastron posteriorly, the entoplastron posteromedially and the other epiplastron medially (NMS G 2004.31.16d and NMS G 1992.47.50; Figs 12, 13). The outer contour of each epiplastron presents two low, rounded protrusions: a first one anterolaterally at the level of the extragular, and a second one anteromedially that may be shared between the two epiplastra. These low protrusions are also present in Kayentachelys aprix and may be the remnants of the well-developed epiplastral tuberosities found in more basal taxa (i.e., Odontochelys semitestacea, Proganochelys quenstedti, Palaeochersis talampayensis and Proterochersis robusta). The posterior contact of the epiplastron with the hyoplastron is transverse and mostly straight. The posteromedial contact with the entoplastron is oblique and straight. The medial contact of the epiplastra prevents the entoplastron from entering the anterior plastral margin, in contrast to basalmost turtles (i.e., Proganochelys quenstedti, Proterochersis robusta, Palaeochersis talampayensis, Kayentachelys aprix and Indochelys spatulata). The morphology of the epiplastron in Eileanchelys waldmani does not resemble that of any other currently known stem turtle, especially not that of Heckerochelys romani in which the epiplastron is an oblique element that tapers posteriorly along the anterolateral margin of the plastron, as also occurs in Mongolochelys efremovi and Meiolania platyceps. On the dorsal surface of the right epiplastron of NMS G 2004.31.16d lies a small, disarticulated rod-like bone that is interpreted as the epiplastral process (Figs 5, 12). The ventral end of this bone expands slightly from the main shaft and has a triangular section. Compared to that of Kayentachelys aprix (Joyce et al. 2006), the ventral part of this process is less expanded. The shaft is partly crushed, but the dorsal part of the element seems to expands slightly and to develop a short longitudinal crest. As preserved this element is $9.5 \mathrm{~mm}$ in length, but the dorsalmost part of it may be crushed below the associated skull (Fig. 5). Basal turtles (i.e., Proganochelys quenstedti, Palaeochersis talampayensis, Odontochelys semitestacea, Proterochersis robusta, Kayentachelys aprix, Heckerochelys romani, Meiolania platyceps, Mongolochelys efremovi and Kallokibotion bajazidi) and at least some crown-group turtles (e.g., some pleurosternids and Xinjiangchelys latimarginalis Young \& Chow, 1953) have a dorsal process on the epiplastron. The nature of this process has been discussed recently. This structure is interpreted by some (e.g., Gaffney 1990) as a simple dorsal extension of the epiplastron. Indeed, a welldeveloped ascending process of the clavicle occurs in many primitive tetrapods (Romer 1956). In contrast, Joyce et al. (2006) reinterpreted this structure as a cleithrum based on newly discovered specimens of Kayentachelys aprix that show a sutural contact between this structure and the epiplastron. Indeed, when disarticulated, this structure leaves a scar on the dorsal surface of the epiplastron that is more similar to a sutural contact than to the broken base of a process (e.g., NHM R3727 and NHM R4317 for Pleurosternon bullockii). The interpretation of Joyce et al. (2006), which is based on morphological evidence, is more appealing, but has recently been questioned because the presence of a cleithrum in turtles would be incongruent with their hypothesised saurian relationships (Rieppel 2008). No matter which interpretation is correct, the presence of cleithra, or epiplastral processes, in Eileanchelys waldmani is a primitive feature. In NMS G 2004.31.16d, this element appears to be disarticulated from the epiplastron at its base suggesting a possible sutural contact with the epiplastron (Fig. 5). If this element is a dorsal process of the epiplastron, a breakage at the base of the process is obviously the less probable scenario as there would be a histological continuity between the main epiplastron and the process. Consequently, the process would have broken anywhere but at its base. This observation is more in agreement with Joyce et al.'s (2006) interpretation of this structure as a cleithrum.

Entoplastron. The entoplastron, which corresponds to the interclavicle of other tetrapods (Zangerl 1939; Walker 1947), is the only unpaired element of the plastron. The entoplastron is preserved in NMS G 2004.31.16d (Fig. 12) and NMS G 1992.47.50 (Fig. 13). It is 

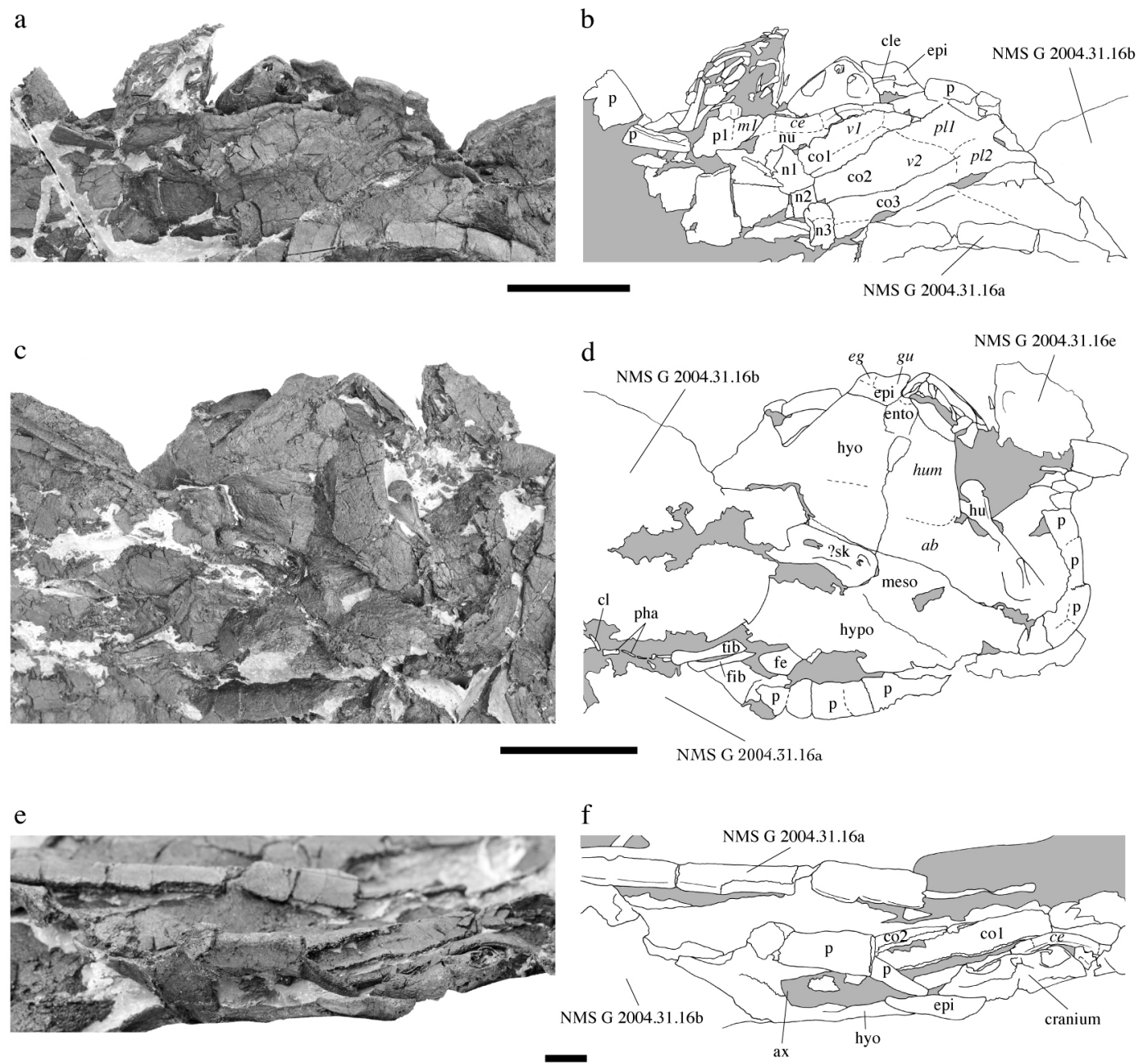

Figure 12 - Eileanchelys waldmani, NMS G 2004.31.16d (shell). (a, b) carapace; (c, d) plastron; (e, f) anterior view. Epidermal scales are in italics. Scale bars: (a-d) $50 \mathrm{~mm}$; (e, f) $10 \mathrm{~mm}$. Abbreviations: ab, abdominal scale; ax, axillary notch; ce, cervical scale; cl, claw; cle, cleithrum; co, costal plate; eg, extragular scale; ento, entoplastron; epi, epiplastron; fe, femur; fib, fibula; gu, gular scale; hu, humerus; hum, humeral scale; hyo, hyoplastron; hypo, hypoplastron; m, marginal scale; meso, mesoplastron; $n$, neural plate; nu, nuchal plate; $p$, peripheral plate; pha, phalange; pl, pleural scale; ?sk, possible skull; tib, tibia; v, vertebral scale.

a diamond-shaped element that is stretched posteriorly. It is elongate, apparently more so in NMS G 2004.31.16d than in NMS G 1992.47.50, but this may be a misleading impression due to the incompleteness of the latter specimen. The entoplastron contacts the epiplastron anterolaterally and the hyoplastron posterolaterally. Proganochelys quenstedti, Palaeochersis talampayensis, Proterochersis robusta, Kayentachelys aprix and Indochelys spatulata each have a distinct, well-developed anterior entoplastral process that reaches the anterior plastral border and that prevents the medial contact of epiplastra. This anterior process is absent in more derived turtles, including Eileanchelys waldmani. Among basal turtles, the entoplastron of E. waldmani is more similar to that of Heckerochelys romani, although the latter is significantly sleeker. The visceral development of the entoplastron is important in turtles: usually the dorsal exposure of the entoplastron is larger than its ventral exposure, and the entoplastron also develops a posterior entoplastral process that extends a variable distance along the visceral surface of the plastron. None of these features is preserved in available specimens of Eileanchelys waldmani.

Hyoplastron. The hyoplastron is a large paired element that contacts the epiplastron anteriorly, the entoplastron anteromedially, the peripherals laterodorsally and the mesoplastron posteriorly (NMS G 2004.31.16a, NMS G 2004.31.16b, NMS G 2004.31.16d and NMS G 1992.47.50; Figs 9, 10, 12 and 13). Posterior to the contact with the entoplastron, the hyoplastra meet one another along the midline. In NMS G 2004.31.16a, a young individual with incomplete ossification, the hyoplastra may have been separated posteriorly along the midline due to the presence of a central plastral fontanelle. However, the presence of such a fontanelle in this specimen is ambiguous because this area is damaged 
a

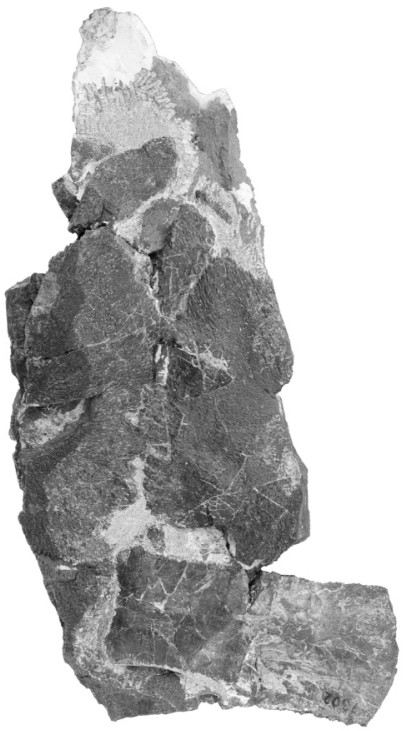

b

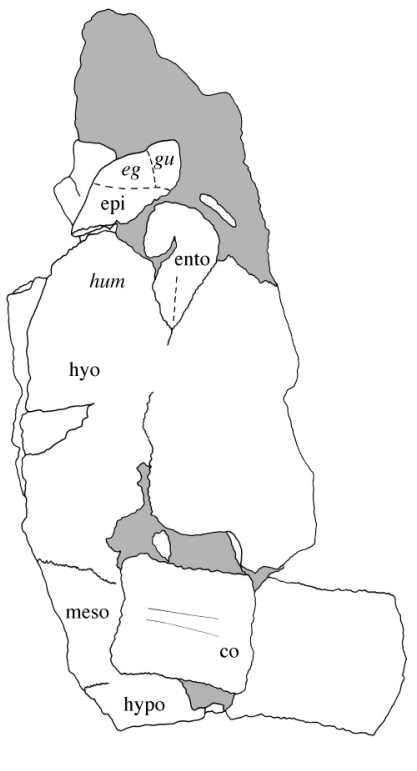

Figure 13 - Eileanchelys waldmani, NMS G 1992.47.50. (a, b) partial plastron. Epidermal scales are in italics. Scale bar: 50 mm. Abbreviations: co, costal plate; eg, extragular scale; ento, entoplastron; epi, epiplastron; gu, gular scale; hum, humeral scale; hyo, hyoplastron; hypo, hypoplastron; meso, mesoplastron.

(see Mesoplastron, below). The lateral part of the hyoplastron greatly extends anterodorsally to meet peripheral 2, thus defining a deep axillary notch (Fig. 9e, f). As no specimen show a visceral view of this part of the plastron or of the carapace, the development of the axillary buttress is unknown in Eileanchelys waldmani. Laterally, the hyoplastron contacts peripherals 2, 3, 4 and most of peripheral 5 (NMS G 2004.31.16a and NMS G 2004.31.16b; Figs 9, 10).

Mesoplastron. The mesoplastron is a dermal, paired element that ossifies between the hyoplastron and the hypoplastron in some turtles. In Eucryptodira and Chelidae, the mesoplastra are lost. In contrast, most stem turtles and paracryptodires have a fully developed mesoplastron that prevents any contact between the hyoplastron and hypoplastron and that usually meets the other mesoplastron medially, unless a central plastral fontanelle is present (e.g., Mongolochelys efremovi). In Kallokibotion bajazidi and most panpleurodires (with the exception of chelids), the mesoplastron is present but reduced to the lateral part of the plastron, so that partial contact between the hyoplastron and hypoplastron is possible medially. Finally, Proterochersis robusta and Odontochelys semitestacea are unique among turtles in having two pairs of mesoplastra. Eileanchelys waldmani, like the majority of stem turtles (with the exception of the two aforementioned species and Kallokibotion bajazidi), has one fully developed pair of mesoplastra that prevents contact between the hyoplastra and hypoplastra (NMS G 2004.31.16a, NMS G 2004.31.16b and NMS G 2004.31.16d; Figs 9, 10 and 12). The mesoplastron contacts the hyoplastron anteriorly, the fifth and sixth peripherals laterally and the hypoplastron posteriorly. The anteroposterior length of the mesoplastron is greatest laterally where it contacts the peripherals, but it tapers slightly toward the midline. In NMS G 2004.31.16a, a central plastral fontanelle, which would prevent the midline contact of the mesoplastra, seems to be present, but because the concerned area is damaged the presence/absence of this feature is ambiguous (Fig. 9c, d). Central plastral fontanelles (i.e., the absence of ossification of the central area of the plastron) occur very commonly in young individuals of many turtle species, including Kayentachelys aprix (Joyce \& Sterli pers. comm. 2007) and NMS G 2004.31.16a is indeed interpreted as a younger individual because of the incomplete ossification of the lateralmost part of the costals (Fig. 9). In NMS G 2004.31.16b (Fig. 10c, d) and NMS G 2004.31.16d (Fig. 12c, d), there is no evidence for a central plastral fontanelle and the mesoplastra appear to meet one another along the midline. As so many turtle species retain fontanelles during ontogeny, these structures are only phylogenetically informative if present in adult individuals. Fossil material rarely offers the opportunity to investigate ontogenetic issues adequately.

Hypoplastron. The hypoplastron is a paired element that forms the posterior part of the bridge and approximately half of the posterior plastral lobe. In Eileanchelys waldmani, the hypoplastron contacts the mesoplastron anteriorly, peripherals 6,7 and 8 laterally, 


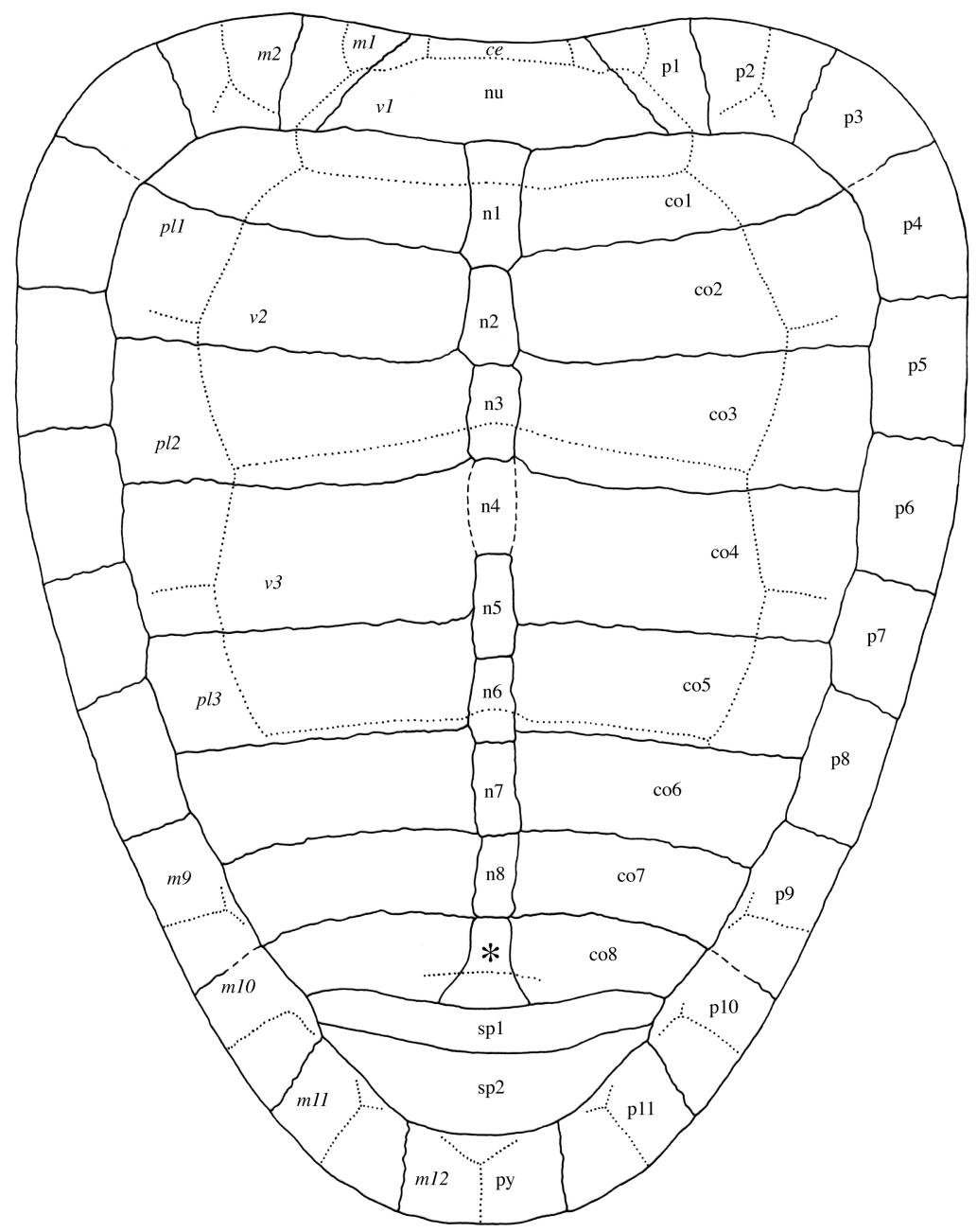

Figure 14 - Tentative reconstruction of the carapace of Eileanchelys waldmani in dorsal view. Epidermal scales are in italics. Abbreviations: ce, cervical scale; co, costal plate; m, marginal scale; $n$, neural plate; nu, nuchal plate; p, peripheral plate; pl, pleural scale; $\mathrm{v}$, vertebral scale.

the xiphiplastron posteriorly and the other hypoplastron medially (NMS G 2004.31.16a and NMS G 2004.31.16b; Figs 9, 10). The lateral part of the hypoplastron supports a posterodorsal process that meets peripheral 8, thus defining the inguinal notch. As no specimen shows a visceral view of this part of the plastron or of the carapace, the development of the inguinal buttress is unknown in Eileanchelys waldmani. The hypoplastraxiphiplastra suture is poorly preserved in all specimens. Laterally, this suture is transverse for a short distance, but becomes arched posteriorly to form a broad 'U'-shape.

Xiphiplastron. The xiphiplastron is a paired element that forms the posterior half of the posterior plastral lobe. In all turtles, including Eileanchelys waldmani, the only contacts of the xiphiplastron are with the hypoplastron anteriorly and the other xiphiplastron medially. In E. waldmani, the xiphiplastron is triangular in shape. Although, the posterior rim of the plastron is not well-preserved in any specimen (NMS G 2004.31.16a and
NMS G 2004.31.16b; Figs 9, 10), there is no evidence for the presence of an anal notch.

Gular scales. The gulars (plastral scale set 1 of Hutchison \& Bramble 1981) are usually paired, but some turtles have only one median gular (e.g., Pleurosternon bullockii and all known panpleurodires; see Joyce 2007). No specimen of Eileanchelys waldmani has a complete anterior plastral rim, so it is uncertain whether there were one or two gular scales. Observation of NMS G 2004.31.16d (Fig. 12C, d) and NMS G 1922.47.50 (Fig. 13) suggests that there were paired gulars, but the midline sulcus between the two scales is not preserved. Actually, plastral scale sulci are poorly preserved in all known specimens of Eileanchelys waldmani. Because paired gulars are present in all stem turtles for which this area of the plastron is known, the following description assumes that two gular scales were present in Eileanchelys waldmani. The gulars were small quadrangular elements that were slightly broader than long and that lay mostly 
on the epiplastra. Anteriorly, the gulars covered most of the anterior tip of the plastron. The gular scale contacted the extragular laterally, the humeral posteriorly and the other gular medially. The gular-extragular sulcus is slightly convex laterally. The gular-humeral sulcus is mostly straight and oblique, facing posterolaterally. Posteromedially, the gular-humeral sulcus runs over the anteriormost part of the entoplastron.

Extragular scales. The extragulars (plastral scale set 2 of Hutchison \& Bramble 1981) are paired scales that are usually located lateral to the gulars. Extragulars are found in all turtles with the exception of most crown-group cryptodires (Joyce 2007). In Eileanchelys waldmani, extragulars were very small scales that lay in the anterolateral corner of the epiplastron (NMS G 2004.31.16d and NMS G 1992.47.50; Figs 12, 13). They consisted of roughly triangular elements that contacted the gular laterally and the humeral posteriorly. The extragular scale bordered the anterior plastral rim and corresponded exactly to the anterolateral low protrusion of the epiplastron (see Epiplastron, above). The sulci of the extragular with the gular and with the humeral are of similar length. The contact with the gular may have been slightly concave.

Humeral scales. The humerals (plastral scale set 3 of Hutchison \& Bramble 1981) are paired scales that cover most of the anterior plastral lobe. In Eileanchelys waldmani, as in most turtles, the humeral contacted the extragular anteriorly, the gular anteromedially, the pectoral posteriorly and the other humeral medially (NMS G 2004.31.16a, NMS G 2004.31.16b and NMS G 2004.31.16d; Figs 9, 10 and 12). The anterior contact with the extragular and gular is almost straight and it faces slightly anteromedially. The posterior sulcus with the pectoral is not preserved entirely in any available specimen, but it appears to have been mostly transverse, maybe slightly convex anteriorly, and it lies entirely on the hyoplastron. Laterally, before reaching the plastral rim, the humeral-pectoral sulcus turns sharply toward the anterior and runs anterolaterally for a short distance. The humeral scale lay on the hyoplastron, the entoplastron and the posterior part of the epiplastron.

Pectoral scales. Pectorals (plastral scale set 4 of Hutchison \& Bramble 1981) are paired scales that usually cover the hyoplastron-mesoplastron suture, when the mesoplastron is present. In Eileanchelys waldmani, the pectoral was present (NMS G 2004.31.16a and NMS G 2004.31.16b; Figs 9, 10) but the pectoral-abdominal sulcus is not preserved in any specimen.

Abdominal scales. Abdominals (plastral scale set 5 of Hutchison \& Bramble 1981) are paired scales that usually cover the mesoplastron-hypoplastron suture, when the mesoplastron is present. As stated above (see Pectoral scales), the pectoral-abdominal sulcus is not preserved in any available specimen of Eileanchelys waldmani. The abdominal-femoral sulcus is located at the same level as the inguinal notch. Starting at the inguinal notch, the sulcus runs anteromedially for a short distance, then curves posteriorly to resume a sub-transverse course. Rather than strictly transverse, the sulcus appears to be slightly convex anteriorly reaching its maximum anterior extent in the midline (Figs 9, 10). This pattern is found commonly among turtles.

Femoral scales. Femorals (plastral scale set 6 of Hutchison \& Bramble 1981) are paired scales that cover at least half, but often more, of the posterior plastral lobe. They also usually cover part, if not all, of the hypoplastron-xiphiplastron suture. The femoral sulci are best seen in NMS G 2004.31.16a (Fig. 9c, d). The femoral consisted of a relatively large quadrangular scale covering two thirds of the posterior plastral lobe. As in all turtles, the femoral contacted the abdominal anteriorly, the anal posteriorly and the other femoral medially. The abdominal-femoral sulcus is described above (see Abdominal scales). The femoral-anal sulcus appears to have been more or less transverse and lies entirely on the xiphiplastron, although this sulcus and the hypoplastronxiphiplastron suture become very close in the midline. In this configuration, the femoral entirely covered the hypoplastron-xiphiplastron suture.

Anal scales. Anals (plastral scale set 7 of Hutchison \& Bramble 1981) are paired scales that cover the posteriormost portion of the plastron. As in all turtles, the anal of Eileanchelys waldmani contacted the femoral anteriorly and the other anal medially (NMS G 2004.31.16a; Fig. 9c, d). The femoral-anal sulcus is described above (see Femoral scales). The anal scale lay entirely on the xiphiplastron and did not overlap the hypoplastron medially.

Inframarginal scales. Inframarginals are paired scales located in the bridge portion of the plastron. Their number is variable among turtles. Stem turtles and most pancryptodires have a complete row of inframarginals that fully separate the marginals from the plastral scales. Testudinoids are characterised by the presence of only two pairs of inframarginal scales: the anterior axillaries and the posterior inguinals. Inframarginals are lost in all known panpleurodires (Joyce 2007). Although NMS G 2004.31.16a and NMS G 2004.31.16b present a relatively well-preserved bridge area, no inframarginal sulci are preserved in any specimen, so that the number and morphology of inframarginal scales in Eileanchelys waldmani remain unknown. 


\section{Postcranial morphology (Figs 15,16 )}

\subsection{Material}

Postcranial turtle material (other than shell) is rare at Cladach a'Ghlinne, which prevents a comprehensive description. However, several specimens preserve limb bones or vertebrae that merit mention. NMS G 2004.31.16a possesses a few articulated cervical vertebrae, but these are so poorly preserved that nothing can be said about their morphology (see Fig. 9). Ventral to the cervical vertebrae, the distal head of either a radius or ulna, as well as some smaller elements that probably pertain to the autopodium, are present. At the level of the right axillary notch, this specimen also possesses a long, thin columnar bone that undoubtedly corresponds to the dorsal process of the scapula (Fig. 9e, f). In NMS G 2004.31.16b, the right hindlimb is folded onto the plastron so that the zeugopodium and a partial autopodium are visible (Fig. 10c, d). In the posterior part of the shell cavity of this specimen, some poorly preserved caudal vertebrae are present, but these are very poorly preserved. Slightly anterior to the anterior carapacial rim of NMS G 2004.31.16c, the incomplete remains of two or three cervical vertebrae are present. It is not clear if these pertain to NMS G 2004.31.16c or to the partial skull NMS G 2004.31.16e (if this skull represents a different individual; see section 3). In NMS G 2004.31.16d, the left humerus and part of the left hindlimb (distal part of the femur, zeugopodium and fragmentary autopodium) are preserved (Fig. 12c, d). A very poorly preserved partial limb (probably a forelimb zeugopodium and autopodium) is present ventral to NMS $G$ 2004.31.16e. This may pertain to either NMS G 2004.31.16c or NMS G 2004.31.16d. NMS G 2004.31.16g consists of a series of cervical vertebrae. NMS G 2004.31.16h represents a partial forelimb: the zeugopodium and possibly the distal part of the humerus. NMS G 2004.31.17 is an isolated left pubis. Finally, NMS G 1992.47.8 is a block of matrix containing shell fragments, a partial ilium and an incomplete hindlimb (femur, tibia and a fragment of fibula).

\subsection{Description}

In NMS G 2004.31.16d (Fig. 12c, d), the humerus is preserved approximately in anatomical position. It appears to be an elongate element relatively to the dimensions of the shell, but this may due to deformation and this is consequently hard to quantify. As preserved, the humerus is straight and exposed in ventral view. The proximal head is greatly eroded, whereas the distal half of the bone is crushed. The morphology of the humerus can be best seen in NMS G 1992.47.51, a small isolated left humerus (Fig. 15a-f). The bone is only slightly curved. The proximal head is eroded, but the ulnar process appears to be more developed than the radial process. The distal head is better preserved and the two condyles for the radius and ulna are visible in ventral view (Fig. $15 c, d)$. Sediment covers the area where the ectepicondylar foramen would be, but a supinator (or supracondylar) process is visible in ventral view. NMS G 2004.31.16h consists of an ulna and radius that may be associated with the distal part of the humerus (Fig. 15g, h). However, the relations of these bones with other specimens in the association are unclear. The ulna and radius have similar dimensions. The ulna is a flattened element, whereas the radius is more rod-like. Both extremities of the ulna are expanded and flattened. The olecranon and sigmoid notch are embedded in the matrix. The proximal head of the radius expands slightly, whereas the distal head is slightly flattened.

The femur is best seen in NMS G 1992.47.8, although the proximal head is broken (Fig. 16). As preserved, the femur is flattened, but this is probably due to deformation. The diaphysis of the femur is relatively broad. The distal head expands slightly, but the state of preservation of this area does not permit further description. The hindlimb zeugopodium is preserved in NMS G 2004.31.16b (Fig. 10c, d), NMS G 2004.31.16d (Fig. 12c, d) and NMS G 1992.47 .8 (Fig. 16). The tibia has a greatly expanded, triangular proximal head. The distal head of the tibia is only slightly expanded. The fibula is a thin, rod-like bone that expands slightly distally. Parts of the hindlimb autopodium are preserved in NMS G 2004.31.16b and NMS G 2004.31.16d, but are difficult to exploit because the connexions between the remaining elements are lost. These remains consist mostly of an assemblage of moderately elongate phalanges and claws (Figs 10c, d and 12c, d). NMS G 1992.47.8 shows a partial ilium (Fig. 16). This bone resembles that of Proganochelys quenstedti and Palaeochersis talampayensis, although it is slightly higher (i.e., the iliac neck is slightly more developed). As in Proganochelys quenstedti and Palaeochersis talampayensis, the posterior iliac process is elongate (Gaffney 1990; Sterli et al. 2007). The morphology of the ilium in Eileanchelys waldmani appears to be intermediate between the primitive morphology seen in Proganochelys quenstedti and Palaeochersis talampayensis and the rather derived morphology seen in Kayentachelys aprix (MCZ 8988). NMS G 2004.31.17 is an isolated left pubis (Fig. 15i-I). It is a triradiate element, with a well-developed medial process. However, the morphology of the thyroid fenestra is unknown. The lateral process is strong and flattened. It is striated at its extremity. The posterior extremity of the posterior 


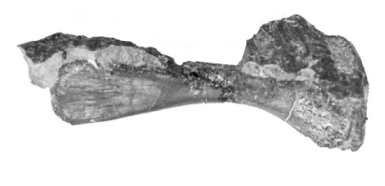

b

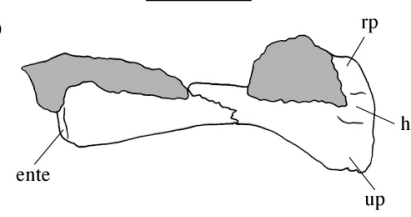

g

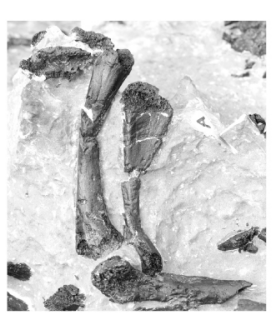

$\mathrm{h}$

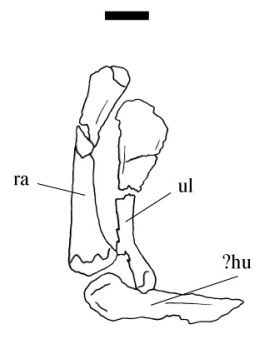

m

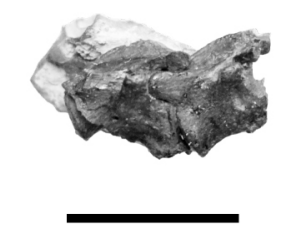

$\mathrm{n}$

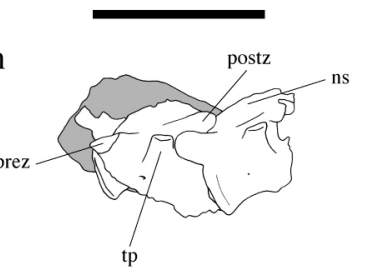

c

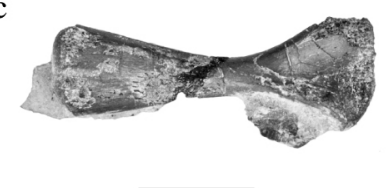

e

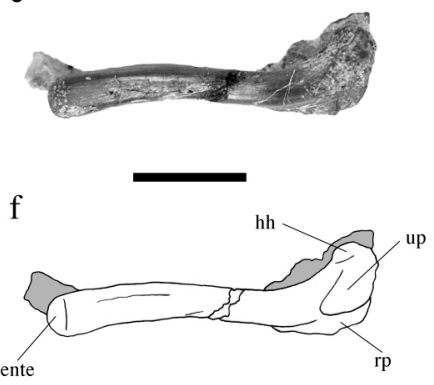

k

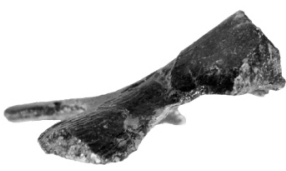

1

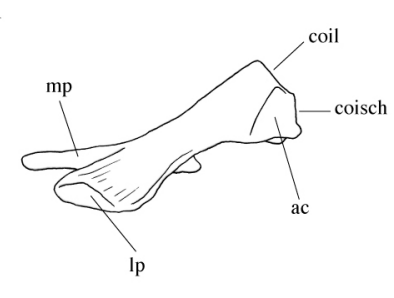

o
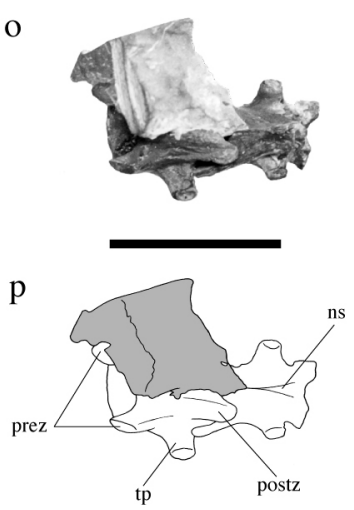

q

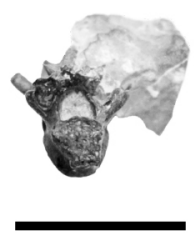

r

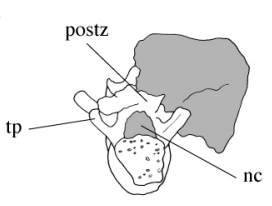

Figure 15 - Eileanchelys waldmani, postcranial material. (a-f), NMS G 1992.47.51, left humerus in dorsal (a, b), ventral (c, d) and posterior (e, f) views; $(g, h)$, NMS G 2004.31.16h, radius and ulna; (i-l), NMS G 2004.31.17, left pubis in ventral $(i, j)$ and lateral $(k, l)$ views; (m-r), NMS G 2004.31.16g, cervical vertebrae (specimen A) in lateral $(m, n)$, dorsal $(o, p)$ and posterior ( $q$, $r$ ) views. Scale bars: $10 \mathrm{~mm}$. Abbreviations: ac, acetabulum; coil, contact with ilium; coisch, contact with ischium; ecte, ectepicondyle; ente, entepicondyle; hh, humeral head; hu, humerus; Ip, lateral process; mp, medial process; nc, neural canal; ns, neural spine; postz, postzygapophysis; prez, prezygapophysis; ra, radius; rp, radial process; sup, supinator process; thf, thyroid fenestra; tp, transverse process; ul, ulna; up, ulnar process.

process shows three surfaces: the lateral surface corresponds to the acetabulum, the dorsomedial surface to the contact with the ilium, and the ventromedial surface to the contact with the ischium.

NMS G 2004.31.16g consists of a series of seven cervical vertebrae in different states of preservation. They cannot be associated with any of the other specimens in the association and it is unclear whether or not they pertain to the same individual. Two of the vertebrae are in articulation (Fig. 15m-r). No atlas or axis can be confidently identified within this assemblage. Apart from one that is very fragmentary, all of the vertebrae are 

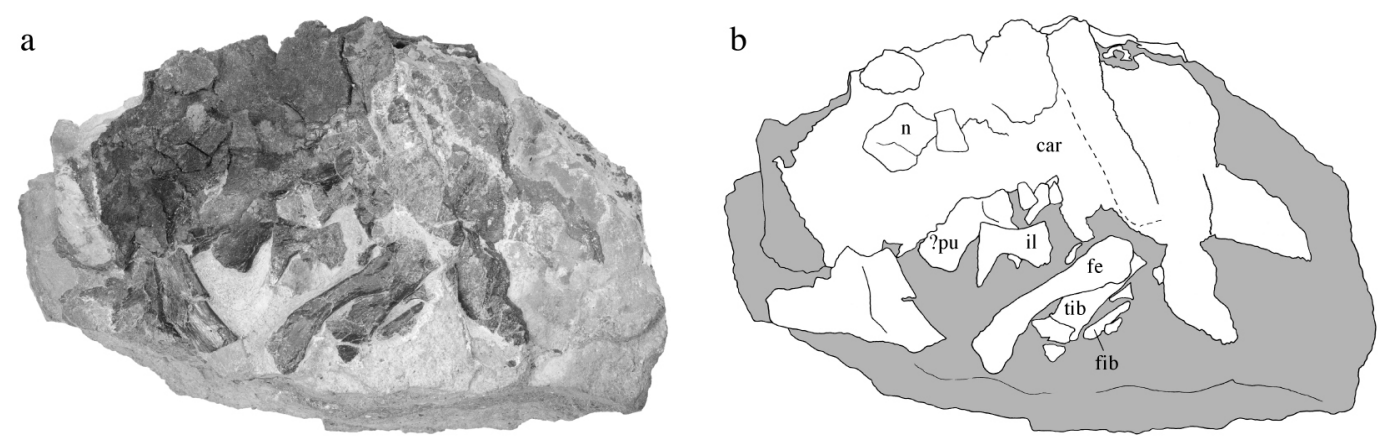

Figure 16 - Eileanchelys waldmani, NMS G 1992.47.8. (a) carapace fragments, partial pelvis and partial hindlimb; (b) key to photograph in (a). Scale bar: 50 mm. Abbreviations: car, carapace fragments; fe, femur; fib, fibula; il, ilium; n, neural plate; pu, pubis; tib, tibia.

similar in morphology. They are distinctly platycoelous, by contrast with the cervical vertebrae found in other stem turtles. In Proganochelys quenstedti, Palaeochersis talampayensis, Kayentachelys aprix and Kallokibotion bajazidi, the cervical centra are amphicoelous, which represents the plesiomorphic condition for Reptilia (e.g., Romer 1956; Hoffstetter \& Gasc 1969). The cervical vertebrae of Meiolania platyceps and Mongolochelys efremovi have formed articular surfaces, as it is the case for all panpleurodires as well as for the clade uniting 'macrobaenids'-'synemydids' and crown-group cryptodires (Joyce 2007). In Eileanchelys waldmani, the articular surface of the centrum of cervical vertebrae is variable in shape from a higher than wide oval to a triangle. As in other turtles, the centrum is laterally hollowed to form a sagittal keel on the ventral surface of the cervical vertebra, but this sagittal keel is only incipient and the centrum has a concave ventral margin in lateral view. The cervical vertebrae are approximately as long as high. The transverse process is located in the middle of the centrum and is directed laterodorsally. There is no other rib process on the cervical vertebra. The neural arch is incipient. The articular surface of the prezygapophyses faces mostly medially with a small dorsal component, but this area can be observed in only one cervical vertebra. The articular surface of the postzygapophyses is oriented at an angle of approximately 45 degrees and faces ventrolaterally, but again, this cannot be determined in all of the preserved vertebrae.

\section{Discussion}

\subsection{Size of Eileanchelys waldmani}

Due to the fact that most specimens are either crushed or fragmented, it is difficult to accurately appraise their size. However, it is apparent that a moderately broad size range characterises the available specimens of Eileanchelys waldmani. Of the four shells found within the association NMS G 2004.31.16 two are smaller in size: NMS G 2004.31.16a and NMS G 2004.31.16b (Table 1). Because of the incomplete ossification of the shell, it has been suggested that NMS G 2004.31.16a represents a younger individual (see sections 5.1 and 5.2). All other known specimens, including NMS G 2004.31.16b, have a completely ossified shell. Although, as preserved, NMS G 2004.31.16b has the same carapace

\begin{tabular}{c|cccc} 
& NMS G 2004.31.16a & NMS G 2004.31.16b & NMS G 2004.31.16c & NMS G 1992.47.50 \\
\hline $\begin{array}{c}\text { Carapace length } \\
(\mathrm{mm})\end{array}$ & $\begin{array}{c}215 \\
\text { (approximative) }\end{array}$ & $\begin{array}{c}233 \\
\text { (postmortem } \\
\text { deformation) }\end{array}$ & 232 & - \\
\hline $\begin{array}{c}\text { Plastron length } \\
(\mathrm{mm})\end{array}$ & 186 & $\begin{array}{c}138 \\
\text { (humeral-pectoral } \\
\text { sulcus to posterior) }\end{array}$ & - & $\begin{array}{c}87.5 \\
\text { (anterior to hyopl.- } \\
\text { mesoplastron suture) }\end{array}$
\end{tabular}

Table 1 - Carapace and plastron length of selected individuals. Due to state of preservation of the material some measurements are approximative or partial. This is stated where appropriate. 


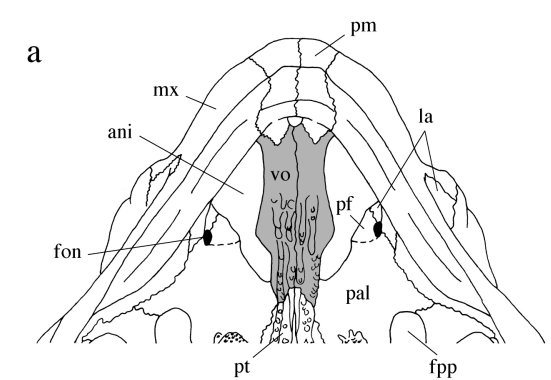

b

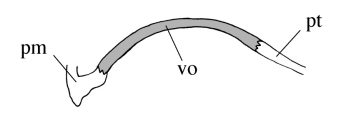

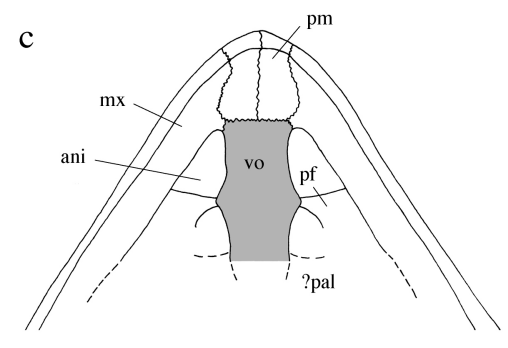

d

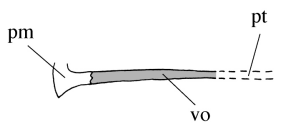

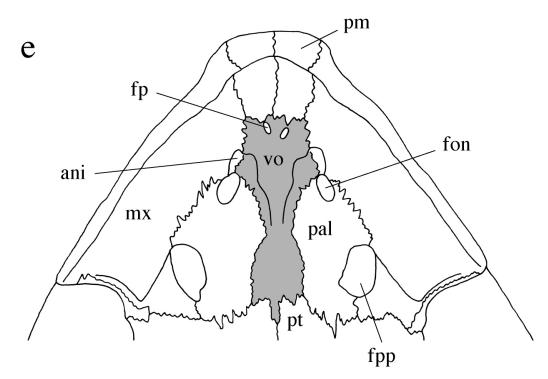

$\mathrm{f}$

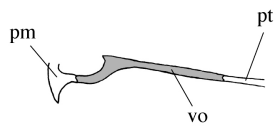

Figure 17 - Evolution of the vomer in basal turtles (modified from Anquetin et al. 2009). (a, b) Proganochelys quenstedti in ventral view (a) and sagittal section (b); (c, d) Eileanchelys waldmani in ventral view (c) and sagittal section (d); (e, f) Chelydra serpentina in ventral view (e) and sagittal section (f). (a) redrawn from Gaffney (1990); (e) redrawn from Gaffney (1979). Abbreviations: ani, apertura narium interna; fon, foramen orbito-nasale; fp, foramen praepalatinum; fpp, foramen palatinum posterius; la, lacrimal; mx, maxilla; pal, palatine; pf, prefrontal; pm, premaxilla; pt, pterygoid; vo, vomer.

length than NMS G 2004.31.16c, this is due to postmortem deformation and NMS G 2004.31.16b would actually be smaller. This is especially obvious when comparing limb bone proportions between NMS G 2004.31.16b and NMS G 2004.31.16d and the dimensions of the costal bones between the former and NMS G 2004.31.16c. A broad size range in the available specimens of Eileanchelys waldmani is also indicated by the thickness of the shell bone in NMS G 2004.31.18 and by the size of the hindlimb bones in NMS G 1992.47.8. All these observations suggest that the carapace length of Eileanchelys waldmani (200-300 mm; see section 3) may have been slightly underestimated. This also indicates that both adult and juvenile individuals lived in the lagoonal palaeoenvironment.

\subsection{Evolution of the vomer}

The vomer in Proganochelys quenstedti, Palaeochersis talampayensis and Australochelys africanus is very different from that found in crown-group turtles. In contrast, the most derived stem turtles known to date (i.e., Meiolania platyceps, Mongolochelys efremovi and Kallokibotion bajazidi) possess a vomer with a modern morphology. Hence, the evolution of the modern chelonian vomer occurred along the phylogenetic stem of Testudines. In Kayentachelys aprix, Heckerochelys romani and Condorchelys antiqua, the vomer is severely damaged, summarily described and not preserved, respectively. Therefore, Eileanchelys waldmani offers a unique opportunity to understand the evolution of the vomer in basal turtles. In the plesiomorphic condition, illustrated by Proganochelys quenstedti (SMNS 15759 and SMNS 16980) and Australochelys africanus (BP/1/4933), the vomer consists of a large sheet of bone that curves dorsally well above the level of the palatine and pterygoid. It is free of contact for most of its length and only contacts the premaxilla and maxilla anteriorly and the pterygoid and palatine posteriorly. The descending process of the prefrontal does not meet the vomer ventrally (Fig. 17a, b). The meatus choanae (i.e., the internal narial canals) are absent and the apertura narium interna consists of large paired openings in the floor of the fossa nasalis. The vomer forms the medial margin of the apertura narium interna. In the next step of its evolution, as documented by Eileanchelys waldmani and also partly by Kayentachelys aprix (MNA V1558 and MCZ 8917; see also Sterli \& Joyce 2007), the vomer becomes a more horizontal sheet of bone in the same plane as the palatine and pterygoid (Fig. 17c, d). At this stage, the meatus choanae are still absent and the vomer forms the medial margin of the paired apertura narium interna. In Eileanchelys waldmani, the descending process of the prefrontal now has a sutural contact with the vomer (Fig. 17c). Sterli \& Joyce (2007) tentatively proposed that this contact was also present in Kayentachelys aprix, but the contact is not actually preserved in any specimen (see section 4.2). In all more derived turtles (i.e., Meiolania platyceps, Mongolochelys efremovi, Kallokibotion bajazidi and crown-group turtles), the vomer progressively develops a three-dimensional morphology with the formation of a ventral sagittal septum that separates the meatus choanae (Fig. 17e, f). Hence, the vomer progressively acquires the dumbbell-shaped cross section that is typical of the majority of turtles, with the ventralmost part of the bone forming a horizontal plate that contributes to the formation of an incipient secondary palate and that floors the meatus choanae. In these forms, the contacts of the vomer with the maxilla and especially the palatine become extensive and the 
vomer is surrounded by bone (Fig. 17e). By developing a ventral septum that meets the premaxillae and maxillae ventrally, the vomer forms the incipient meatus choanae and the apertura narium interna is differentiated from the paired openings in the floor of the fossa nasalis. Although they are only incipient in most turtles (e.g., Chelydra serpentina), the meatus choanae are greatly developed in those turtles with an extensive secondary palate (e.g., chelonioids).

\subsection{Aditus canalis stapedio-temporalis and canalis cavernosus}

The well-preserved cavum acustico-jugulare of NMS G 2004.31.15 (Fig. 4), the holotype of Eileanchelys waldmani, documents a further step in the evolution of this area toward the modern morphology seen in crown-group turtles. The cavum acustico-jugulare is a structure found only in turtles and corresponds to a subdivision of the middle ear (the anatomical region between the tympanum and the fenestra ovalis). In turtles, the middle ear region is divided into two parts by a constriction of the quadrate around the columella auris (i.e., the stapes). This is achieved in all turtles with the exception of Proganochelys quenstedti, Palaeochersis talampayensis and Australochelys africanus (Joyce 2007). Proganochelys quenstedti is unique among turtles in having an open cranioquadrate space (plesiomorphic amniote condition; Romer 1956; Gaffney 1990), which allows the passage of nerves and arteries, such as the vena capitis lateralis (the lateral head vein). Proganochelys quenstedti is also unique in having a passage for the stapedial artery (there is no proper canal) that is formed by the processus paroccipitalis of the opisthotic and quadrate, rather than by the prootic and quadrate as in other turtles, and that is located posterior to the fenestra ovalis (plesiomorphic amniote condition; Romer 1956; Gaffney 1990; Joyce 2007). In Palaeochersis talampayensis and Australochelys africanus, the basipterygoid articulation is fused and the pterygoid encloses the vena capitis lateralis forming a short canalis cavernosus that is located approximately at the level of the former articulation. The location of the passage of the stapedial artery is unclear in these taxa (Gaffney \& Kitching 1995; Sterli et al. 2007), but in any case there is no opening between the processus paroccipitalis of the opistothic and the quadrate, unlike the condition present in Proganochelys quenstedti. Moreover, several holes in the roof of the middle ear cavity of BP/1/4933, the holotype and only specimen of Australochelys africanus, might correspond to the passage of the stapedial artery (pers. obs.). If this is the case, then the passage would be located approximately at the same level than the fenestra ovalis in this species. In all more derived turtles, including Kayentachelys aprix and
Eileanchelys waldmani, there is a well-developed canal for the stapedial artery that is formed by the quadrate and prootic, the canalis stapedio-temporalis. Ventrally, this canal opens into the roof of the cavum acustico-jugulare via the aditus canalis stapedio-temporalis. In Kayentachelys aprix (MCZ 8917) and Eileanchelys waldmani (NMS G 2004.31.15; Fig. 4), the aditus canalis stapediotemporalis is situated at the level of the anterior wall of the fenestra ovalis, whereas in all more derived turtles it is positioned anterior to the fenestra ovalis. This suggests a progressive anterior migration of the aditus canalis stapedio-temporalis relative to the fenestra ovalis in stem turtles.

In comparison with Palaeochersis talampayensis and Australochelys africanus, the length of the canalis cavernosus increases in Kayentachelys aprix, Eileanchelys waldmani, Heckerochelys romani and Condorchelys antiqua with the progressive posterior development of the pterygoid along the basisphenoid, which results in a more posterior location of the posterior opening of this canal in these species. There seems to be a progressive posterior migration of the posterior opening of the canalis cavernosus in these species: the opening is located slightly more anteriorly in Kayentachelys aprix than in Eileanchelys waldmani and Heckerochelys romani, whereas it is slightly more posterior in Condorchelys antiqua. It is remarkable that in these turtles the aditus canalis stapedio-temporalis and the posterior opening of the canalis cavernosus are widely separated from one another (e.g., Fig. 4). In more derived turtles, the posterior opening of the canalis cavernosus is located further posteriorly and is actually very close to the aditus canalis stapedio-temporalis. Hence, the recent reassessment of the cranial material of Kayentachelys aprix (Sterli \& Joyce 2007) and the present description of Eileanchelys waldmani allow a better understanding of the evolution of the middle ear region in basal turtles, especially by documenting the progressive forward migration of the aditus canalis stapedio-temporalis and backward migration of the posterior opening of the canalis cavernosus.

\section{Acknowledgements}

Fieldwork was funded by the National Geographic Society (awarded to Susan Evans). I extend my sincere appreciation to all members of the field party, especially Marc Jones, Richard Butler, Dave Herd, Jason Hilton and Jolyon Parish who collected the paratype association under extremely difficult conditions. The National Museums of Scotland provided logistic support, while Scottish Nature and the John Muir Trust are thanked for permission to work at the locality. I am also indebted to 
Scott Moore-Fay (Palaeontology Conservation Unit, NHM) for his supervision and advice during preparation of the turtle material from Skye. Photographs of the turtle cranial material from Skye were taken by Phil Crabb and Phil Hurst (NHM Image resources). Rainer Schoch and Andreas Matzke (SMNS), Bernhard Zipfel and Bruce Rubidge (BP), Johannes Müller (MB), Janet Gillette (MNA), Patricia Holroyd (University of California Museum of Paleontology, Berkeley), Charles Schaff (MCZ), Timothy Rowe (TMM) and Walter Joyce (then of the Yale Peabody Museum, New Haven) are thanked for granting access to specimens in their care. Walter Joyce and Andreas Matzke provided meticulous reviews of this work and their comments helped to improve the quality of the paper. Paul Barrett and Susan Evans also provided valuable comments on an earlier version of this manuscript. This work was funded by a PhD studentship from the Natural History Museum, London.

\section{References}

Andrews, J. E. 1985. The sedimentary facies of a Late Bathonian regressive episode: the Kilmaluag and Skudiburgh Formations of the Great Estuarine Group, Inner Hebrides, Scotland. Journal of the Geological Society of London 142, 1119-1137.

Anquetin, J. 2009. A new stem turtle from the Middle Jurassic of the Isle of Skye, Scotland, and a reassessment of basal turtle relationships. PhD Dissertation, UCL, University College London.

Anquetin, J., Barrett, P. M., Jones, M. E. H., Moore-Fay, S. \& Evans, S. E. 2009. A new stem turtle from the Middle Jurassic of Scotland: new insights into the evolution and palaeoecology of basal turtles. Proceedings of the Royal Society of London, B 276(1658), 879-886.

Anquetin, J. \& Claude, J. 2008. Reassessment of the oldest British turtle: Protochelys from the Middle Jurassic Stonesfield Slate of Stonesfield, Oxfordshire, UK. Geodiversitas 30(2), 331-344.

Barrett, P. M. 2006. A sauropod dinosaur tooth from the Middle Jurassic of Skye, Scotland. Earth and Environmental Science Transactions of the Royal Society of Edinburgh 97, 25-29.

Baur, G. 1887. Ueber den Ursprung der Extremitäten des Ichthyopterygia. Bericht über die XX. Versammlung des Oberrheinischen Geologischen Vereins 20, 17-20.

Bonin, F., Devaux, B. \& Dupré, A. 2006. Turtles of the world. Baltimore: John Hopkins University Press. [Translated by P. C. H. Pritchard]
Brinkman, D. B. \& Wu, X.-C. 1999. The skull of Ordosemys, an Early Cretaceous turtle from Inner Mongolia, People's Republic of China, and the interrelationships of Eucryptodira (Chelonia, Cryptodira). Paludicola 2(2), 134-147.

Danilov, I. G. \& Parham, J. F. 2008. A reassessment of some poorly known turtles from the Middle Jurassic of China, with comments on the antiquity of extant turtles. Journal of Vertebrate Paleontology 28(2), 306-318.

Datta, P. M., Manna, P., Ghosh, S. C. \& Das, D. P. 2000. The first Jurassic turtle from India. Palaeontology 43(1), 99-109.

Evans, S. E., Barrett, P. M., Hilton, J., Butler, R. J., Jones, M. E. H., Liang, M.-M., Parish, J. C., Rayfield, E. J., Sigogneau-Russell, D. \& Underwood, C. J. 2006. The Middle Jurassic vertebrate assemblage of Skye, Scotland. In Barrett, P. M. \& Evans, S. E. (eds.) Ninth International Symposium on Mesozoic Terrestrial Ecosystems and Biota, Abstract and Proceedings, 36-39. London: The Natural History Museum.

Evans, S. E. \& Waldman, M. 1996. Small reptiles and amphibians from the Middle Jurassic of Skye, Scotland. In Morales, M. (ed.), The Continental Jurassic, 219-226. Museum of Northern Arizona Bulletin 60.

Fang, Q. 1987. A new species of Middle Jurassic turtle from Sichuan. Acta Herpetologica Sinica 6(1) 65-69.

Fraas, E. 1913. Proterochersis, eine pleurodire Schildkröte aus dem Keuper. Jahreshefte des Vereins für vaterländische Naturkunde in Württemberg 69, 13-30.

Gaffney, E. S. 1972. The systematics of the North American family Baenidae (Reptilia, Cryptodira). Bulletin of the American Museum of Natural History 147(5), 241-320.

Gaffney, E. S. 1979. Comparative cranial morphology of recent and fossil turtles. Bulletin of the American Museum of Natural History 164, 65-375.

Gaffney, E. S. 1983. The cranial morphology of the extinct horned turtle, Meiolania platyceps, from the Pleistocene of Lord Howe Island. Bulletin of the American Museum of Natural History 175, 361-479.

Gaffney, E. S. 1990. The comparative osteology of the Triassic turtle Proganochelys. Bulletin of the American Museum of Natural History 194, 1-263.

Gaffney, E. S. 1996. The postcranial morphology of Meiolania platyceps and a review of the Meiolaniidae. Bulletin of the American Museum of Natural History 229, 1-166.

Gaffney, E. S., Hutchison, J. H., Jenkins, F. A. \& Meeker, L. J. 1987. Modern turtle origins: the oldest known 
Gaffney, E. S., Hutchison, J. H., Jenkins, F. A. \& Meeker, L. J. 1987. Modern turtle origins: the oldest known cryptodire. Science 237, 289-291.

Gaffney, E. S., Meylan, P. A. \& Wyss, A. R. 1991. A computer assisted analysis of the relationships of the higher categories of turtles. Cladistics 7(4), 313-335.

Gaffney, E. S. \& Jenkins, F. A. In press. The cranial morphology of Kayentachelys, an Early Jurassic cryptodire, and the early history of turtles. Acta Zoologica.

Gaffney, E. S. \& Kitching, J. W. 1994. The most ancient African turtle. Nature 369, 55-58.

Gaffney, E. S. \& Kitching, J. W. 1995. The morphology and relationships of Australochelys, an Early Jurassic turtle from South Africa. American Museum Novitates 3130, $1-29$.

Gaffney, E. S. \& Meylan, P. A. 1988. A phylogeny of turtles. In Benton, M. J. (ed.), The Phylogeny and Classification of the Tetrapods, Volume 1: Amphibians, Reptiles, Birds, 157-219. Oxford: Clarendon Press.

Gaffney, E. S. \& Meylan, P. A. 1992. The Transylvanian turtle, Kallokibotion, a primitive cryptodire of Cretaceous age. American Museum Novitates 3040, 1-37.

Gillham, C. 1994. A fossil turtle (Reptilia: Chelonia) from the Middle Jurassic of Oxfordshire, England. Neues Jahrbuch der Geologie und Paläontologie. Monatshefte 10, 581-596.

Harris, J. P. \& Hudson, J. D. 1980. Lithostratigraphy of the Great Estuarine Group (Middle Jurassic), Inner Hebrides. Scottish Journal of Geology 16(2-3), 231-250.

Hirayama, R., Brinkman, D. B. \& Danilov, I. G. 2000. Distribution and biogeography of non-marine Cretaceous turtles. Russian Journal of Herpetology 7, 181-198.

Hoffstetter, R. \& Gasc, J.-P. 1969. Vertebrae and ribs of modern reptiles. In Gans, C., Bellairs, A. \& Parsons, T. S. (eds.), Biology of the Reptilia, Volume 1, 201-310. London \& New York: Academic Press.

Hudson, J. D. 1983. Mesozoic sedimentation and sedimentary rocks in the Inner Hebrides. Proceedings of the Royal Society of Edinburgh 83B, 47-63.

Hutchison, J. H. \& Bramble, D. M. 1981. Homology of the plastral scales of the Kinosternidae and related turtles. Herpetologica 37, 73-85.

Jamniczky, H. A. 2008. Turtle carotid circulation: a character analysis case study. Biological Journal of the Linnean Society 93, 239-256.

Jamniczky, H. A., Brinkman, D. B. \& Russell, A. P. 2006. Phylogenetic implications of turtle cranial circulation: a review. In Danilov, I. G. \& Parham, J. F. (eds.), Fossil Turtle
Research, Vol. 1, 84-92. Russian Journal of Herpetology 13(Suppl.).

Jamniczky, H. A. \& Russell, A. P. 2007. Re-appraisal of patterns of turtle carotid circulation: evidence from osteological correlates and soft tissues. Journal of Morphology 268, 571-587.

Joyce, W. G. 2007. Phylogenetic relationships of Mesozoic turtles. Bulletin of the Peabody Museum of Natural History 48(1), 3-102.

Joyce, W. G., Parham, J. F. \& Gauthier, J. A. 2004. Developing a protocol for the conversion of rank-based taxon names to phylogenetically defined clade names, as exemplified by turtles. Journal of Paleontology 78(5), 989-1013.

Joyce, W. G., Jenkins, F. A. Jr. \& Rowe, T. 2006. The presence of cleithra in the basal turtle Kayentachelys aprix. In Danilov, I. G. \& Parham, J. F. (eds.), Fossil Turtle Research, Vol. 1, 93-103. Russian Journal of Herpetology 13(Suppl.).

Karl, H.-V. \& Tichy, G. 2000. Murrhardtia staeschei n. gen. n. sp. - eine neue Schildkröte aus der Oberen Trias von Süddeutschland. Joannea Geologie und Paläontologie 2, 57-72.

Khozatsky, L. I. 1997. Big turtle of the Late Cretaceous of Mongolia. Russian Journal of Herpetology 4(2), 148-154.

Klein, I. T. 1760. Klassification und kurze Geschichte der Vierfüßigen Thiere. Lübeck: Jonas Schmidt. [Translated by F. D. Behn]

Li, C., Wu, X.-C., Rieppel, O., Wang, L.-T. \& Zhao, L.-J. 2008. An ancestral turtle from the Late Triassic of southwestern China. Nature 456, 497-501.

Matzke, A. T., Maisch, M. W., Sun, G. E., Pfretzschner, H.-U. \& Stöhr, H. 2005. A new Middle Jurassic xinjiangchelyid turtle (Testudines; Eucryptodira) from China (Xinjiang, Junggar Basin). Journal of Vertebrate Paleontology 25, 63-70.

Meylan, P. A. \& Gaffney, E. S. 1989. The skeletal morphology of the Cretaceous cryptodiran turtle, Adocus, and the relationships of the Trionychoidea. American Museum Novitates 2941, 1-60.

Nessov, L. A. 1995. On some Mesozoic turtles of the Fergana Depression (Kyrgyzstan) and Dzhungar Alatau Ridge (Kazakhstan). Russian Journal of Herpetology 2, 134-141.

Nopcsa, F. 1923. On the geological importance of the primitive reptilian fauna in the uppermost Cretaceous of Hungary; with a description of a new tortoise (Kallokibotion). Quarterly Journal of the Geological Society 
(Kallokibotion). Quarterly Journal of the Geological Society 79(1), 100-116.

Owen, R. 1886. Description of fossil remains of two species of a Megalania genus (Meiolania, Ow.), from Lord Howe's Island. Proceedings of the Royal Society of London 40, 315-316.

Rieppel, O. 2008. The relationships of turtles within amniotes. In Wyneken, J., Godfrey, M. H. and Bels, V. (eds.), Biology of Turtles, 345-353. Boca Raton, FL: CRC Press.

Romer, A. S. 1956. Osteology of the Reptiles. Chicago: University of Chicago Press.

Rougier, G. W., de la Fuente, M. S. \& Arcucci, A. B. 1995. Late Triassic turtles from South America. Science 268, 855-858.

Savage, R. J. G. 1984. Mid Jurassic mammals from Scotland. In Reif, W.-E. \& Westphal, F. (eds.), Third Symposium on Mesozoic Terrestrial Ecosystems, Short Papers, 211-213. Tübingen: Attempto Verlag.

Scheyer, T. M. \& Anquetin, J. 2008. Bone histology of the Middle Jurassic turtle shell remains from Kirtlington, Oxfordshire, England. Lethaia 41, 85-96.

Shaffer, H. B., Meylan, P. A. \& McKnight, M. L. 1997. Tests of turtle phylogeny: molecular, morphological, and paleontological approaches. Systematic Biology 46(2), 235-268.

Sterli, J. 2008. A new, nearly complete stem turtle from the Jurassic of South America with implications for turtle evolution. Biology Letters 4(3), 286-289.

Sterli, J., de la Fuente, M. S. \& Rougier, G. W. 2007. Anatomy and relationships of Palaeochersis talampayensis, a Late Triassic turtle from Argentina. Palaeontographica, Abteilung A 281(1-3), 1-61.

Sterli, J. \& Joyce, W. G. 2007. The cranial anatomy of the Early Jurassic turtle Kayentachelys aprix. Acta Palaeontologica Polonica 52(2), 675-694.

Sukhanov, V. B. 2000. Mesozoic turtles of Middle and Central Asia. In Benton, M. J., Shishkin, M. A., Unwin, D. M. \& Kurochkin, E. N. (eds.), The age of dinosaurs in Russia and Mongolia, 309-367. Cambridge: Cambridge University Press.

Sukhanov, V. B. 2006. An archaic turtle, Heckerochelys romani gen. et sp. nov., from the Middle Jurassic of Moscow region, Russia. In Danilov, I. G. \& Parham, J. F. (eds.), Fossil Turtle Research, Vol. 1, 112-118. Russian Journal of Herpetology 13(Suppl.).
Tong, H., Buffetaut, E. \& Suteethorn, V. 2002. Middle Jurassic turtles from southern Thailand. Geological Magazine 139(6), 687-697.

Waldman, M. \& Evans, S. E. 1994. Lepidosauromorph reptiles from the Middle Jurassic of Skye. Zoological Journal of the Linnean Society 112, 135-150.

Waldman, M. \& Savage, R. J. G. 1972. The first Jurassic mammal from Scotland. Journal of the Geological Society $128,119-125$.

Walker, W. F., Jr. 1947. The development of the shoulder region of the turtle, Chrysemys picta marginata, with special reference to the primary musculature. Journal of Morphology 80, 195-249.

Ye, X. 1982. Middle Jurassic turtles from Sichuan, SW China. Vertebrata Palasiatica 20(4), 282-290.

Ye, X. 1994. Fossil and recent turtles of China. Beijing: Science Press.

Ye, Y. \& Pi, X. 1997. A new genus of Chengyuchelyidae from Dashanpu, Zigong, Sichuan. Vertebrata Palasiatica 35(3), 182-188.

Young, C. C. \& Chow, M. C. 1953. New fossil reptiles from Szechuan, China. Acta Scientia Sinica 2(3), 216-229.

Zangerl, R. 1939. The homology of the shell elements in turtles. Journal of Morphology 65(3), 383-406.

Zangerl, R. 1969. The turtle shell. In Gans, C., Bellairs, A. \& Parsons, T. S. (eds.), Biology of the Reptilia, Volume 1, 311-339. London \& New York: Academic Press. 